\title{
Use-Dependent Modulation of Inhibitory Capacity in the Feline Lumbar Spinal Cord
}

\author{
Niranjala J. K. Tillakaratne, ${ }^{1}$ Ray D. de Leon, ${ }^{1}$ Thao X. Hoang, ${ }^{1}$ Roland R. Roy, ${ }^{3}$ V. Reggie Edgerton, ${ }^{1,3}$ and \\ Allan J. Tobin $1,2,3,4$ \\ Departments of ${ }^{1}$ Physiological Science and ${ }^{2}$ Neurology, ${ }^{3}$ Brain Research Institute, and ${ }^{4}$ Molecular Biology Institute, \\ University of California, Los Angeles, Los Angeles, California 90095-1761
}

The ability to perform stepping and standing can be reacquired after complete thoracic spinal cord transection in adult cats with appropriate, repetitive training. We now compare $\mathrm{GAD}_{67}{ }^{\mathrm{A}}$ levels in the spinal cord of cats that were trained to step or stand. We confirmed that a complete spinal cord transection at $\sim$ T12 increases glutamic acid decarboxylase (GAD) ${ }_{67}$ in both the dorsal and ventral horns of L5-L7. We now show that step training decreases these levels toward control. Kinematic analyses show that this downward modulation is correlated inversely with stepping ability. Compared with intact cats, spinal cord-transected cats had increased punctate $\mathrm{GAD}_{67}$ immunoreactivity around neurons in lamina IX at cord segments L5-L7. Compared with spinal nontrained cats, those trained to stand on both hindlimbs had more $\mathrm{GAD}_{67}$ puncta bilaterally in a subset of lamina IX neurons. In cats trained to stand unilaterally, this elevated staining pattern was limited to the trained side and extended for at least $4 \mathrm{~mm}$ in the L6 and L7 segments. The location of this asymmetric $\mathrm{GAD}_{67}$ staining corresponded to the motor columns of primary knee flexors, which are minimally active during standing, perhaps because of extensor-activated inhibitory interneuron projections. The responsiveness to only a few days of motor training, as well as the GABA-synthesizing potential in the spinal cord, persists for at least 25 months after the spinal cord injury. This modulation is specific to the motor task that is performed repetitively and is closely linked to the ability of the animal to perform a specific motor task.

Key words: standing; stepping; EMG activity; $G A D_{67} ; G A B A$; spinal transection
The lumbar spinal cord relies on supraspinal input and complex sensory information from the periphery to modulate hindlimb motor output. After complete low-thoracic spinal cord transection, supraspinal connections to and from the lumbosacral spinal cord are lost, and peripheral sensory information, including proprioceptive and cutaneous input, is severely disrupted, resulting in hindlimb paralysis. When appropriate sensory stimuli associated with weight bearing and hindlimb activity are provided repeatedly, however, spinal animals can reacquire stepping or standing (Lovely et al., 1986, 1990; Barbeau and Rossignol, 1987; de Guzman et al., 1991; Edgerton et al., 1997, 1998, 2001; de Leon et al., 1998a,b). However, a spinal cat trained to step cannot stand very well and vice versa. Changes in the hindlimb muscles do not account for this recovery (Roy and Acosta, 1986; Roy et al., 1991, 1998, 1999), so the plasticity must reside within the spinal cord.

Other studies of spinally transected animals are consistent with a significant level of plasticity of the spinal circuitry associated

\footnotetext{
Received July 27, 2001; revised Jan. 14, 2002; accepted Jan. 28, 2002.

This work was supported by National Institutes of Health Grants NS16333 and NS22256, a National Research Service Award to N.J.K.T., and the Council on Research of the University of California, Los Angeles (UCLA) Academic Senate. We thank Sharlene Lauretz for excellent care of the animals, Drs. Hui Zhong and John Hodgson for help with tissue dissections, Michelle Mouria, Nurit Ziv, Christine Tran, and Henry Sebata for technical support, Uday Patel for help with constructing the three-dimensional image, Drs. Robert Elashoff and He-Jing Wang (Department of Biostatistics, UCLA) for help with the statistical analyses, and Allison Bigbee for many helpful discussions.

Correspondence should be addressed to Niranjala J. K. Tillakaratne, Gonda (Goldschmied) Neuroscience and Genetics Research Center, 695 Charles Young Drive South, P.O. Box 951761, University of California, Los Angeles, Los Angeles, CA 90095-1761. E-mail: nirat@lifesci.ucla.edu.

R. D. de Leon's present address: Department of Kinesiology, California State University, Los Angeles, CA 90032-8162.

Copyright (C) 2002 Society for Neuroscience $\quad 0270-6474 / 02 / 223130-14 \$ 15.00 / 0$
}

with hindlimb function (Buerger and Fennessy, 1971; Grau et al., 1998). Furthermore, operant conditioning experiments showed that monkeys and rats can be trained to decrease or increase hindlimb Hoffman reflex responses, although this training is not linked to practice of a motor task (Chen and Wolpaw, 1995, 1997; Chen et al., 1999). This modulation persists after spinalization, indicating that some of the learning that occurred could be attributable to changes in the spinal cord itself (Fengchen and Wolpaw, 1996). Other evidence of activity-dependent modulation of spinal networks comes from studies of "spinal fixation," i.e., central or peripheral induction of asymmetric hindlimb positioning (Steinmetz et al., 1981, 1982, 1985).

The specific cellular mechanisms responsible for activitydependent learning in the spinal cord are unknown. Our previous studies suggest, however, that the spinal cords of nontrained and well trained spinal cats have fundamentally different properties, at least with respect to inhibitory processes (Edgerton et al., 1997; de Leon et al., 1999). For example, after spinal cord transection of adult cats, modest doses of strychnine (a glycine receptor antagonist) administered to nontrained or poorly stepping cats lead to a significant improvement in stepping ability (de Leon et al., 1999). Similarly, bicuculline (a $\mathrm{GABA}_{\mathrm{A}}$ receptor antagonist) improved locomotion in nontrained spinal cats that had poor stepping capability before drug administration (Robinson and Goldberger, 1986; Edgerton et al., 1997). In contrast, intact or well trained step-trained spinal cats did not improve their stepping ability after the administration of these drugs (Edgerton et al., 1997; de Leon et al., 1999). There are no studies that provide insight into the biochemical adaptations in the spinal cord of spinal-transected cats that could account for the changes in 
motor performance after practice of specific motor tasks or after selected pharmacological modulations.

We have reported dramatically higher levels of the GABA synthetic enzyme glutamic acid decarboxylase $(\mathrm{GAD})_{67}$ and its mRNA in spinal-transected than intact adult cats (Tillakaratne et al., 2000). In the present study, we examined whether the motor training of spinal cord-transected cats modulates $\mathrm{GAD}_{67}$ in lumbar spinal neurons in a task-specific manner.

\section{MATERIALS AND METHODS}

Animals. Twenty-nine adult female cats (8 intact and 21 spinal cordtransected) were used in the present experiments (Table 1). Cats that had undergone complete low-thoracic spinal cord transection were maintained for 3-25 months.

Spinal cord transection. During all surgical procedures, sodium pentobarbital ( $35 \mathrm{mg} / \mathrm{kg}$, i.p.) was administered to each cat after pretreatment with atropine sulfate $(0.9 \mathrm{mg} / \mathrm{kg}$, s.c.) and acepromazine maleate $(10$ $\mathrm{mg} / \mathrm{kg}$, i.m.). Supplemental doses of the anesthetic were administered as needed during surgery to maintain a low level of arousal.

The spinal cords of the cats were transected completely as described previously (Roy et al., 1992). Briefly, a skin incision was made on the back to expose the vertebral processes between T10 and L1. A partial laminectomy was performed to expose the spinal cord between T11 and T13. Fine scissors were used to open the dura and to transect the bulk of the spinal cord. Fine forceps and miniature cotton balls were used to complete the transection while preserving the ventral artery. The completeness of the transection was easily verified as the spinal cord retracted at both ends, leaving a 3-5 $\mathrm{mm}$ space. Gelfoam was inserted between the two ends; the area was thoroughly flushed with saline; and the muscle and skin above the lesion site were closed with sutures. Postspinalization management of the spinal cats was performed as described previously (Roy et al., 1992). After all surgical procedures, the animals were placed in a warm incubator and allowed $1 \mathrm{~d}$ of recovery before they were returned to their cages.

Antibiotics were administered twice daily to each animal for 1 week after surgery. The cats were housed in spacious cages, two to four cats per cage. After spinal cord transection, the cage floors were covered with shredded newspaper, and the bladders and colons of the cats were expressed daily. Dry kibble and water were given ad libitum, and wet food was given once daily. All procedures were performed in accordance with the following guidelines: care and use of laboratory animals prepared by the Institute of Laboratory Animal Resources for the National Institutes of Health, the American Association for the Accreditation of Laboratory Animal Care, and the Chancellor's Animal Research Committee at the University of California, Los Angeles.

Implantation of electromyographic electrodes. Approximately 2 months before spinal cord transection, electromyographic (EMG) wires were implanted into selected flexor and extensor muscles of the hindlimbs of some cats (soleus, medial gastrocnemius, tibialis anterior, semitendinosus, vastus lateralis, gluteus medius, and iliopsoas) as described by Pierotti et al. (1989). EMG and video recordings during treadmill locomotion were initiated after 1 week of recovery and continued for the full duration of the study. EMG activity during stepping and standing was recorded periodically in animals that had undergone multiple training paradigms; i.e., some cats were trained to stand and then to step and vice versa. All data presented were taken during the last training mode as shown in Table 1.

Hindlimb training and testing procedures. The training and testing procedures have been described in detail previously (de Leon et al., 1998a,b). Briefly, a cloth harness was fitted over the shoulders, between the forelimbs, and around the upper trunk. The forelimbs of the cats rested on a platform raised $\sim 2.5 \mathrm{~cm}$ above the training surface during all training and testing procedures. After spinalization, training of bipedal hindlimb stepping or standing was performed for $30 \mathrm{~min} / \mathrm{d}, 5 \mathrm{~d} /$ week (for details, see de Leon et al., 1998a,b). Stepping ability during a locomotor test was measured by counting the number of plantar steps, i.e., the number of full weight-bearing steps executed on the soles of the paws in the two hindlimbs at a speed of $0.4 \mathrm{~m} / \mathrm{sec}$ during a $45 \mathrm{sec}$ trial. Full weight-bearing steps occurring on the dorsum of the paw were not included in the plantar step number. To train full weight-bearing bilateral hindlimb standing, the hindpaws were placed on the plantar surfaces, and the skin around the knee or ankle was patted lightly or pinched to elicit extensor reflexes. These stimuli were not used to maintain standing but were delivered when necessary to reinstate standing when the hindlimbs collapsed to a sitting, non-weight-bearing position. To train unilateral standing, weight bearing was allowed in only one hindlimb (trained limb) while the other limb (nontrained limb) was held above the training surface (de Leon et al., 1998b). The trainers held the tail only to provide lateral support during standing. To maintain lateral stability during unilateral standing, it was necessary to shift the weight of the hindquar-

\section{Table 1. Summary of postoperative training status and tissue analysis procedures}

Postoperative duration (months)

\section{Intact}

Transected, nontrained

$$
3
$$

6

9

12

$25^{b}$

Transected, step-trained

$\begin{array}{ll}6^{b} & 1 \\ 6 & 1 \\ 12 & 3 \\ 18^{b} & 1 \\ 25^{b} & 1\end{array}$

Transected, stand-trained

$6^{b}-1$

6

$18^{b}$

$3 \quad 2$
Training status at time of termination

Nontrained

Nontrained

Nontrained

Nontrained

Nontrained

Nontrained for 5 months ${ }^{a}$

Nontrained for 10 months

Step-trained for 3 months

Step-trained for 5 months

Step-trained for 1 week $^{c}$

Step-trained for 12 months

Step-trained for 10 months

Stand-trained bilaterally for 3 months

Stand-trained bilaterally for 5 months

Stand-trained bilaterally for 12 months

Stand-trained unilaterally for 3 months
Method of tissue analysis

IHC, ISH

Immunoblots

IHC, ISH

IHC, ISH

IHC, ISH

Immunoblots

IHC, ISH

IHC, ISH

IHC, ISH

Immunoblots

IHC, ISH

IHC, ISH

IHC, ISH

IHC, ISH

IHC, ISH

IHC, ISH

IHC, Immunohistochemistry; ISH; in situ hybridization.

${ }^{a}$ Step training for 2 months followed by no training during the next 5 months.

${ }^{b}$ Animals that had undergone multiple training paradigms (also see Materials and Methods).

${ }^{c}$ Similar to ${ }^{a}$, except retrained to step for 1 week before termination. 
ters onto the trained limb. Typically, the trainers held the paw of the nontrained limb and moved it posteriorly and dorsally to near the base of the tail, resulting in the hindquarters leaning toward the weight-bearing limb. To evaluate standing ability after spinalization, weight bearing in one or both hindlimbs was initiated using the same stimuli that were used during training. After a weight-bearing posture was attained, the initiating stimuli were avoided, allowing the hindlimbs to stand until they collapsed to a sitting, non-weight-bearing position. Several bouts of standing were initiated to ensure a consistent performance.

EMG and kinematic data during stepping were recorded as described by de Leon et al. (1994). Briefly, raw EMG signals were amplified and recorded on a frequency modulation (FM) tape recorder (XR-510; TEAC Corp., Montebello, CA), and a camera and videocassette recorder (WV D5100 camera and AG1280P recorder; Panasonic, Cypress, CA) were used to record the video signals. A Society of Motion Picture and TV Engineers time code generator (F30, Fast Forward Video, Irvine, CA) was used to synchronize video frames with the EMG signals recorded on FM tape. The EMG signals from each muscle during 10-45 sec bouts of stepping or standing were sampled into an Amiga computer at $2 \mathrm{kHz}$ (de Leon et al., 1998a,b, 1999).

Tissue processing. Both intact $(n=4)$ and spinal cord-transected $(n=$ 14) cats (except those used for immunoblot analysis) were perfused intracardially with $4 \%$ formaldehyde in $0.12 \mathrm{~m}$ phosphate buffer. The entire spinal cord, including the transection site, was removed, post-fixed in the fixative solution for $2 \mathrm{hr}$, and washed with $0.12 \mathrm{M}$ phosphate buffer (four times, $30 \mathrm{~min}$ each). The cords then were transferred to $30 \%$ sucrose for $2 \mathrm{~d}$, embedded on OCT-Tissue Tek (Miles, Elkhart, IN), and frozen on dry ice. Tissues were stored at $-70^{\circ} \mathrm{C}$ until analysis.

Transverse sections (30 $\mu \mathrm{m}$ thick) of fixed spinal cords (L5-L7) were cut using a cryostat and collected free-floating in PBS. After washing in PBS, adjacent sections were processed for immunohistochemistry, in situ hybridization, or histochemical staining. The tissue sections used to compare the experimental groups were processed simultaneously. To minimize tissue damage that may occur with tissue handling, we processed free-floating sections using a netwell setup (75 $\mu \mathrm{m}$ mesh; Costar, Cambridge, MA). Spinal cord sections in netwells were transferred sequentially to netwell trays containing appropriate solutions. Incubation with cRNA probes, antibodies, and ribonuclease A (Sigma, St. Louis, $\mathrm{MO})$ and color reactions were performed in 24-well plates.

The lesion sites from each cat were evaluated for completeness of the transection by histological analysis of $20 \mu \mathrm{m}$ sagittal sections (thawed on slides) with luxol blue (myelin) and cresyl violet (neurons and glia) stains (Kluver and Barrera, 1953).

Immunohistochemistry. Sections were processed for immunohistochemistry using an avidin-biotin complex (ABC)-peroxidase system (ABC Elite; Vector Laboratories, Burlingame, CA) as described previously (Esclapez et al., 1994; Tillakaratne et al., 2000). Sections from spinal cord segments L5-L7 from control and spinal cats were incubated in 1:3000 or 1:4000 dilutions of K2 polyclonal antibody, which mainly recognizes $\mathrm{GAD}_{67}$ (Kaufman et al., 1991). The monoclonal antibody GAD6, which specifically recognizes $\mathrm{GAD}_{65}$, was used at a 1:100 dilution (Chan and Gottlieb, 1988; Erlander et al., 1991). To optimize cell body staining, we did not use detergents in the procedure. The sections were first rinsed in $0.02 \mathrm{~mm}$ potassium PBS (KPBS; in mM: $16.5 \mathrm{~K}_{2} \mathrm{HPO}_{4}, 3.5$ $\mathrm{KH}_{2} \mathrm{PO}_{4}$, and $150 \mathrm{NaCl}$ ) for $30 \mathrm{~min}$ and then incubated with $3 \%$ normal serum (NS) diluted in KPBS for $1 \mathrm{hr}$ (blocking step), followed by incubation with the antibody diluted in $1 \%$ NS for $16-20 \mathrm{hr}$ at room temperature. Normal goat serum and normal horse serum (Vector Laboratories) were used for $\mathrm{GAD}_{67}$ and $\mathrm{GAD}_{65}$, respectively. Sections were rinsed three times, followed by two $10 \mathrm{~min}$ washes in KPBS. Sections then were incubated with the biotinylated secondary antibody (1:200 in $1 \% \mathrm{NS}$ ) for $1 \mathrm{hr}$. Sections were washed and incubated in avidin-biotin complex (A and B reagents at 1:100 in KPBS) for $1 \mathrm{hr}$. The sections were washed and reacted with the DAB and $\mathrm{H}_{2} \mathrm{O}_{2}$ (Sigma). Color development was monitored and ranged from 10 to $13 \mathrm{~min}$. The time of the color development within an experiment was held constant. The sections were washed and mounted on superfrost slides (Fisher Scientific, Pittsburgh, PA), air-dried, and coverslipped with cytoseal (Stephens Scientific). Washings after primary, secondary, and ABC immunohistochemistry and color development were performed as described above.

In situ hybridization. Antisense and sense cRNA $\mathrm{GAD}_{67}$ probes were transcribed from subclones 13 and 16 of feline BamHI-linearized GAD $_{67}$ cDNA using Sp6 RNA polymerase and digoxigenin-11-UTP (Roche Molecular Biochemicals, Indianapolis, IN) (Kaufman et al., 1986; Wuenschell et al., 1986; Tillakaratne et al., 2000). Digoxigenin-labeled RNA probes were partially digested with alkali to fragments $150-500$ bases long, and their concentrations were measured as described previously (Esclapez et al., 1993, 1994; Tillakaratne et al., 2000). Sections were hybridized with digoxigenin-labeled cRNA $(0.2 \mathrm{ng} / \mathrm{ml})$ for $\sim 16 \mathrm{hr}$ at $50^{\circ} \mathrm{C}$ and washed as described previously (Esclapez et al., 1993, Tillakaratne et al., 2000). The hybrids were detected immunologically by incubation with alkaline phosphatase-conjugated digoxigenin antibody (Roche Molecular Biochemicals) followed by nitroblue tetrazolium chloride-5-bromo-4-chloro-3-indolylphosphate color development.

Immunoblots. L5 and L6 segments of unfixed spinal cords (four intact, four nontrained, and three step-trained spinal cord-transected cats whose spinal cords were transected 12 months earlier; see Table 1) were cut into lengths of $\sim 3-4 \mathrm{~mm}$ and sonicated in homogenization buffer $(100 \mathrm{mg}$ tissue/ml; Tillakaratne et al., 2000). The homogenization buffer consisted of $60 \mathrm{~mm}$ phosphate buffer, $\mathrm{pH} 7.4,1 \mathrm{~mm}$ phenylmethylsulfonyl fluoride, and $0.5 \%$ Triton X-100. The homogenates were centrifuged for $15 \mathrm{~min}$ at $100,000 \times g$ using a TL100 ultracentrifuge (Beckman Instruments, Palo Alto, CA), and the total protein in the supernatants was measured by the Bradford assay (Bio-Rad, Hercules, CA). For immunoblot analyses, proteins $(30 \mu \mathrm{g})$ were separated by SDS-PAGE.

Ten $50-\mu \mathrm{m}$-thick L6 spinal cord transverse sections were pooled to make the protein homogenates for slot blot quantification. Spinal cord homogenates were loaded into the wells of a slot blot apparatus (Schleicher \& Schuell, Keene, NH). After blotting onto nitrocellulose membranes, we detected $\mathrm{GAD}_{67}$ and $\beta$-tubulin proteins by enhanced chemiluminescence (ECL; Amersham Biosciences, Arlington Heights, IL). We determined the dilutions of the primary and secondary antibodies that yielded consistent quantitative results. Blots were incubated overnight at $4^{\circ} \mathrm{C}$ with $\mathrm{K} 2$ (anti-GAD ${ }_{67}$ at 1:3000) or anti- $\beta$ tubulin at $1: 3000$ (Chemicon, Temecula, CA) after blocking for $1 \mathrm{hr}$ at room temperature with $10 \%$ nonfat milk in PBS containing $0.1 \%$ Tween 20 (PBST). After washing with PBST, the blots were incubated with the appropriate secondary antibody (1:2000) for $1 \mathrm{hr}$ at room temperature. Antibody dilutions were made in PBST containing 5\% nonfat milk. Washing between incubations consisted of three quick rinses, one 15 min rinse, and four $5 \mathrm{~min}$ rinses in PBST. Signals were visualized by ECL and exposure to $\mathrm{x}$-ray film. The films then were scanned using an image analysis system (C-Imaging; Compix Inc., Cranberry Township, PA) to determine the optical density of the protein bands. This protocol gives a linear standard curve using bacterially produced $\mathrm{GAD}_{67}$. Using total protein concentrations that were in the linear range of ECL detection $(50-15 \mu \mathrm{g})$, we compared $\mathrm{GAD}_{67}$ levels after correcting for differences in loading and transfer by normalizing to $\beta$-tubulin in the same blots (Tillakaratne et al., 2000). It was possible to use the same blots two or three times with the same limits of immunodetection.

Microscopic analysis. The uniformity of tissue processing is a critical factor when analyzing the staining patterns and intensity between animals. Thus, primary fixation, post-fixation, and tissue processing were similar for the spinal cord sections prepared for immunohistochemistry or for in situ hybridization. The cat cerebellum was used as a positive control for immunohistochemistry and for in situ hybridization. The specificity of the GAD immunostaining was confirmed by the presence of GAD-immunoreactive neurons and punctate structures in the cerebellar cortex (Esclapez et al., 1993, 1994). Specificity also was confirmed by the lack of staining in tissue sections that had been incubated without the primary antibody or with the sense cRNA probe. Spinal cord transverse sections of the L5-L7 segments of intact and spinal cord-transected cats to be compared were run concurrently either for immunohistochemistry or for in situ hybridization. The time of color development within an experiment was held constant. Adjacent spinal cord sections processed for $\mathrm{GAD}_{67}$ and $\mathrm{GAD}_{65}$ were examined for the differential immunostaining reported for $\mathrm{GAD}_{67}$ but not for $\mathrm{GAD}_{65}$ after spinal cord transection (Tillakaratne et al., 2000). Cresyl violet and luxol blue staining of sections was used to evaluate the number and size of neurons.

Spinal cord sections of control and spinally transected cats, processed concurrently, were used for qualitative and semiquantitative analyses. Images to be compared were acquired with a Zeiss (Thornwood, NY) Axiophot microscope equipped with a Sony-3 CCD color camera under identical conditions (magnification, light levels, and other microscopic settings), and saved as tagged image file format files. The images were analyzed by C-Imaging software (Compix). Work files were customized for each measurement. Threshold values were set to discriminate the signal from the background. The identified objects were viewed as a green binary overlay displayed over the original image. Measurements included the staining intensity of $\mathrm{GAD}_{67}$ immunoreactivity in the lateral 
ventral horn of individual neurons in lamina IX and of $\mathrm{GAD}_{67}$ mRNA in individual neurons of medial and lateral laminas $\mathrm{V}$ and VI and the medial and lateral ventral horns. Regions of interest (ROIs; subregions or individual neurons) for optical density measurements were outlined manually on the saved images. Pixels outside the ROIs were removed using the qualify feature. We added the edit option on the work file to erase, redraw, or individually remove obvious background spots before the final data acquisition. The zoom and roam feature was used on the image on display for detailed examination. The customized work files were saved and loaded to collect data from the saved images and the data were copied to Excel spreadsheets (Microsoft, Redmond, WA) and analyzed statistically. The cross-sectional areas of individual neurons were measured, and the optical density of staining was measured as the total object area. The total object area then was calculated with respect to the area of the ROI.

$\mathrm{GAD}_{67}$-positive neurons in medial lamina IX were captured at $250 \times$ at identical illumination. For the optical density measurements, individual neurons (a total of 120 neurons per cat) were outlined manually. The optical density of staining was measured as the total object area inside the outlined area (ROI). The mean $\mathrm{GAD}_{67}$ immunostaining in lamina IX in control and experimental animals (except in the unilaterally standtrained cats) was calculated using 120 lamina IX neurons from each animal. The distribution and analysis of $\mathrm{GAD}_{67}$ immunostaining in unilaterally stand-trained cats were determined from 25 sequential transverse sections ( $30 \mu \mathrm{m}$ thick, each taken at $\sim 120 \mu \mathrm{m}$ ) of the L5-L7 spinal segments processed for $\mathrm{GAD}_{67}$. We first compared the total object area in all of the $\mathrm{GAD}_{67}$ neurons in the contralateral and ipsilateral lamina IX region. For detailed analysis, individual $\mathrm{GAD}_{67}$-positive neurons in lamina IX of 25 sections were captured at $500 \times$ at identical illumination. The amount of $\mathrm{GAD}_{67}$ staining in individual neurons on the ipsilateral and contralateral sides (a total of 464 neurons) was measured as described above. The mean immunoreactivity per neuron between the trained and nontrained sides was compared using $t$ tests. The number of positively stained cells was divided into four groups using the labeling intensity values (strongest, $1.00-0.80$; strong, 0.79-0.60; medium, 0.590.40 ; and low, <0.39). These values were used to add pseudocolors to neurons in the three-dimensional (3-D) representation of the $\mathrm{GAD}_{67}$ staining (see Fig. 5; also see below). We used the $\chi^{2}$ test to determine whether the frequencies of cells in each intensity range were significantly different between the contralateral and ipsilateral sides (see Fig. 5).

The amount of $\mathrm{GAD}_{67}$ mRNA levels in individual neurons in the medial and lateral areas of laminas V and VI and the ventral horn (from eight sections) were measured as described above. Differences in the mean immunoreactivity per neuron among the four groups were compared using the mixed model (see below). Positively stained cells were subdivided into two groups using the labeling intensity values (high, $\geq 0.3$; and low, $<0.3$ ). We used the $\chi^{2}$ test to determine whether the frequencies of cells in the intensity ranges were significantly different among the four groups (see Fig. 9).

3-D reconstruction of $G A D_{67}$-immunoreactive neurons. Sequential (1:4 series) transverse spinal cord sections ( $30 \mu \mathrm{m}$ thick) of the L5-L7 segments of the unilaterally stand-trained cats were processed for $\mathrm{GAD}_{67}$ (1:3000, K2 antibody), $\operatorname{GAD}_{65}(1: 100$, GAD6), or cresyl violet staining. The spinal cord sections with $\mathrm{GAD}_{67}$ staining were analyzed at $31 \times$ magnification to capture the entire right or left half of the spinal cord. Overlapping images of these sections were used in Figure 4.

To make a 3-D reconstruction, we used 6 of the 25 spinal cord sections processed for immunohistochemistry (see above). The actual positions of the $\mathrm{GAD}_{67}$-positive neurons in each section were copied to separate transparencies. A digitizing program was used to incorporate $x, y$, and $z$ coordinates of the $\mathrm{GAD}_{67}$-positive neurons. The position of these neurons and the corresponding optical density and size measurements then were used to construct a $3-\mathrm{D}$ image of the $\mathrm{GAD}_{67}$ immunostaining with the 3-D-Studio Max program (Kinetix).

Statistical analyses. Computer-based resampling ("bootstrap") software (version 4.0.2; Resampling Stats, Arlington, VA) and a mixed model were used to determine differences in group means (intact vs spinal, intact vs trained, and trained vs nontrained) as described previously (Efron and Tibshirani, 1993; de Leon et al., 1998a,b). A mixed model was used to study the differences in $\mathrm{GAD}_{67}$ staining among the experimental groups. The model used was: $Y_{\mathrm{ijg}}=\alpha_{\mathrm{i}}+\beta_{\mathrm{g}}$, where $Y_{\mathrm{ijg}}$ is the $j$ th measurement of $\mathrm{GAD}_{67}$ staining for subject $i$ in group $g, \alpha_{\mathrm{i}}$ is the intercept for subject $i$, and $\beta_{\mathrm{g}}$ is the effect of group $g$ (Efron and Tibshirani, 1993; Tillakaratne et al., 2000). The significance level was set at $p<0.05$.

\section{RESULTS}

\section{Stand training and step training evoke distinct alterations in $\mathrm{GAD}_{67}$ levels}

We examined $\mathrm{GAD}_{67}$ expression in the lumbar spinal cord of intact and spinally transected cats with a monospecific polyclonal antibody raised against recombinant cat $\mathrm{GAD}_{67}$. In intact animals, moderate levels of $\mathrm{GAD}_{67}$ immunoreactivity were visible as puncta on and around lamina IX neurons (Fig. 1A). Chronic spinally transected cats, in contrast, contained elevated levels of $\mathrm{GAD}_{67}$ punctate staining on and around the somata of lamina IX neurons (Figs. $1 B-E, 2 B, C, 3 F$ ). In addition, neurons in the spinal cats showed diffuse $\mathrm{GAD}_{67}$ staining in the somata. We observed similar patterns of $\mathrm{GAD}_{67}$ immunoreactivity $3,6,18$, and 25 months after complete spinal cord transection (Figs. 1-3).

Spinal cats trained daily to step for $3,5,10$, or 12 months showed reduced $\mathrm{GAD}_{67}$ immunoreactivity compared with nontrained spinal cats [Fig. 1, $D, E$ compared with $B(5$ and 10 months); data for 3 and 12 months not shown]. The step-trained cats showed lower diff use cell body staining and punctate staining bilaterally in lamina IX neurons than in non-trained cats (Fig. 1, compare $D, E$ with $B)$. In contrast, cats trained to stand bilaterally for 3 (data not shown), 5 (Fig. $1 C$ ) or 12 (Fig. 2C) months showed stronger punctate $\mathrm{GAD}_{67}$ staining in a subset of lamina IX neurons. Compared with control cats $(6.25 \pm 2.54 ; n=4)$, the higher $\mathrm{GAD}_{67}$ staining in lamina IX neurons in the nontrained $(14.95 \pm 2.26 ; n=5 ; p=0.01)$ and bilaterally stand-trained $(16.27 \pm 3.59 ; n=3 ; p=0.02)$ cats was statistically significant. The level of $\mathrm{GAD}_{67}$ staining in step-trained $(8.58 \pm 2.92 ; n=4$; $p=0.55)$ cats, however, was similar to that in control cats. One hundred twenty lamina IX neurons per animal from all nontrained, step-trained, and bilaterally stand-trained cats (except the groups used for immunoblot analyses; Table 1) were included for the above comparisons.

\section{The patterns of EMG activity of hindlimb muscles reflect the type of motor training}

To determine whether the training protocols elicit appropriate activation of the motor pools, we examined the EMG patterns of selected hindlimb muscles during treadmill locomotion. Steptrained spinal cats showed well coordinated EMG bursts in both flexor and extensor muscles controlling the hip, knee, and ankle joints (Fig. $1 G, H$ ). Stand-trained cats also generated substantial bursts of EMG activity when tested for stepping. The EMG bursts, however, were irregular and poorly coordinated (Fig. 1I). The stepping ability of the stand-trained cats was limited, and some of these cats did not perform any full weight-bearing stepping. The hindlimb muscles of these cats, however, showed nearnormal EMG activity during standing (Fig. $1 F$ ) (de Leon et al., 1998b). Many of the spinal animals were not trained continuously in one training mode from the point of spinal cord transection to the time of EMG recording (see Materials and Methods). The EMG patterns recorded during the step tests, however, corresponded consistently with the most recent training paradigm.

\section{Unilateral stand training results in an asymmetry of $\mathrm{GAD}_{67}$ immunoreactivity in a subset of neurons within ipsilateral lamina IX}

To examine the specificity of the training effects on spinal animals, we trained two animals to stand on one leg for 12 weeks. Unilateral standing was evident after training even when the hindlimbs were placed in a position to stand bilaterally (Fig. 3, compare $G, H$ ). These data are consistent with a detailed analysis 

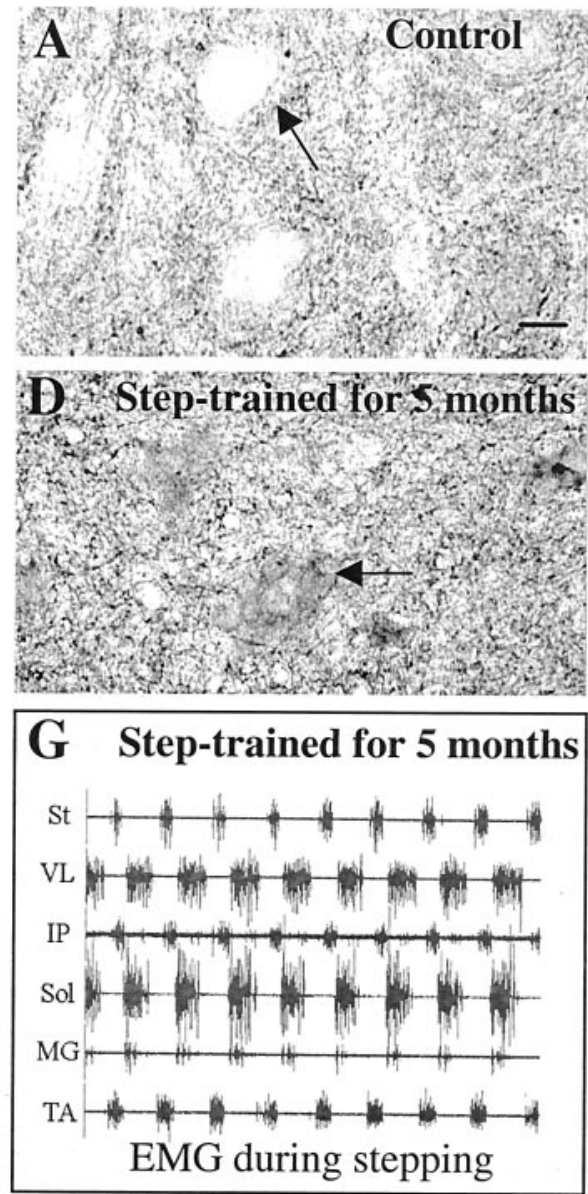
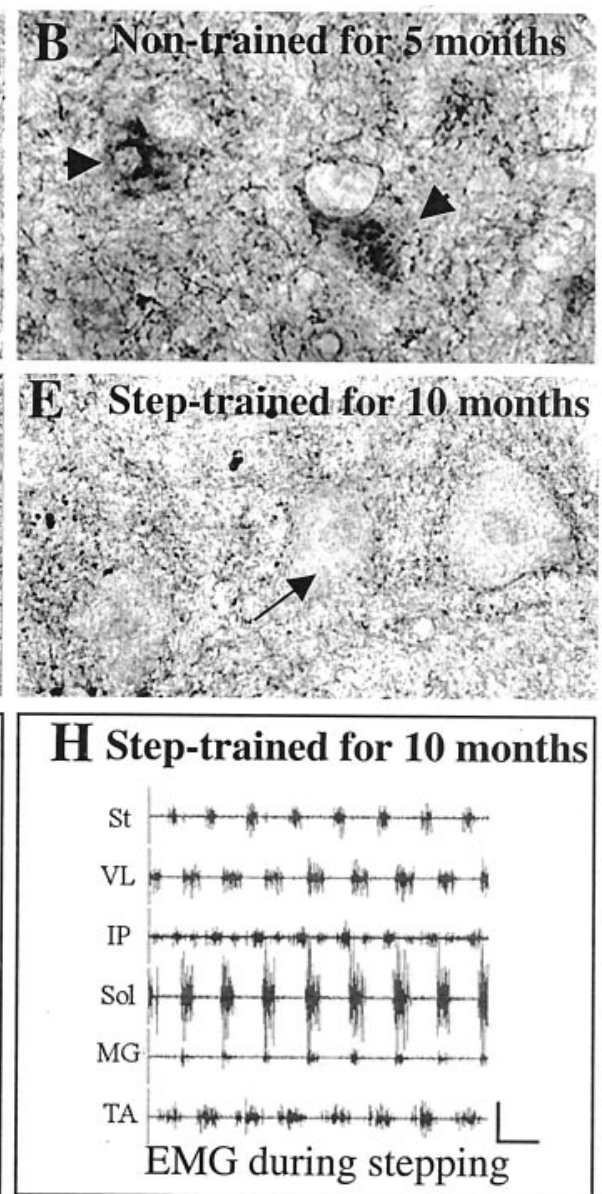
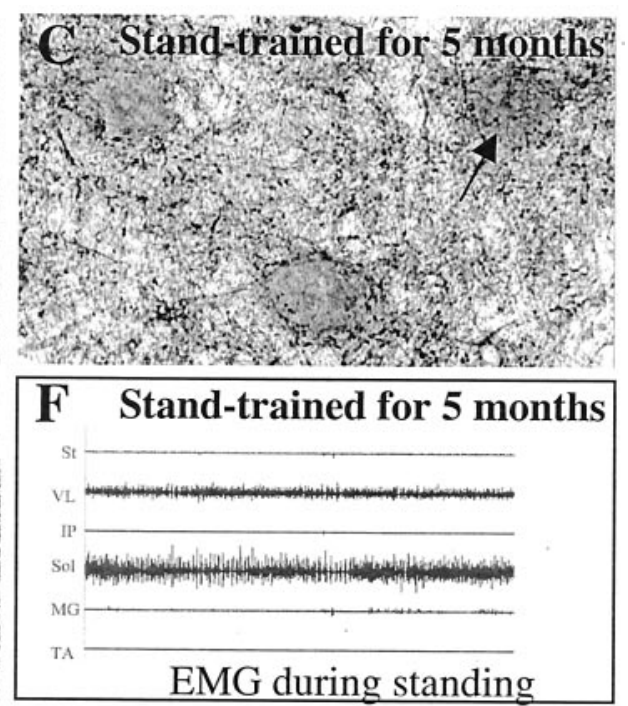

I Stand-trained for 5 months

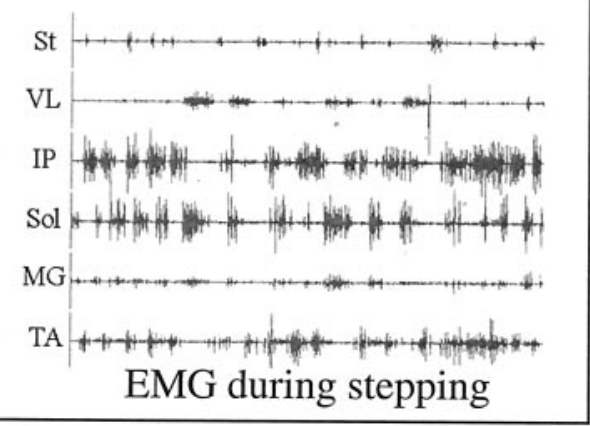

Figure 1. $\mathrm{GAD}_{67}$ immunoreactivity in L6 lamina IX neurons and hindlimb EMG activity patterns reflect the type of motor training performed after low-thoracic spinal cord transection. Transverse sections of the L6 segment of the lumbar spinal cord were immunolabeled with an antibody to GAD 67

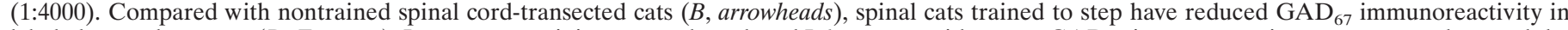
labeled ventral neurons $(D, E$, arrow $)$. In contrast, training to stand produced L6 neurons with strong $\mathrm{GAD}_{67}$-immunoreactive puncta on and around the soma of lamina IX neurons ( $C$, arrows). $A$, Control; $B, 6$ months after transection, nontrained; $C, 6$ months after transection, trained to stand bilaterally for the last 5 months; $D, 6$ months after transection, trained to step for the last 5 months; $E, 25$ months after transection, trained to step for the last 10 months. Scale bar, $25 \mu \mathrm{m}$ (applies to $A-E$ ). $F$, Corresponding EMG activity in hindlimb muscles during bilateral standing for the cat shown in $C$; $G-I$, corresponding EMG activity in hindlimb muscles during bilateral stepping for the cats shown in $D, E$, and $C$, respectively. Note that the semitendinosus $(S t)$, a knee flexor, is inactive during stance $(I)$. An alternating flexor and extensor EMG activity pattern during stepping is observed in the step-trained $(G, H)$, but not the stand-trained $(I)$ spinal cats. $V L$, Vastus lateralis; $I P$, iliopsoas; Sol, soleus; $M G$, medial gastrocnemius; $T A$, tibialis anterior. Calibration: $1 \mathrm{sec}, 1 \mathrm{mV}$.

of unilateral stand training published previously (de Leon et al., 1998b). For example, substantial EMG in the soleus and modest EMG in the vastus lateralis were detected in the limb trained to support the body weight during standing. In contrast, minimal EMG activity was observed in these extensor muscles in the nontrained contralateral limb.

Unilateral stand training evoked a clear asymmetry in the intensity and pattern of $\mathrm{GAD}_{67}$ staining. For example, compared with the nontrained side, $\mathrm{GAD}_{67}$ staining was higher in a localized area in lamina IX of the trained side (Fig. $3 A-F$ ). This asymmetrical $\mathrm{GAD}_{67}$ immunoreactivity in the ventral horn of L6-L7 was observed for at least $4 \mathrm{~mm}$ longitudinally, and the topographical location corresponds to that of the semimembranosus and semitendinosus motor columns (Vanderhorst and Holstege, 1997) (Fig. 4). The $\mathrm{GAD}_{67}$ immunoreactivity in lamina IX neurons (measured in 25 sequential spinal cord sections spanning $\sim 3 \mathrm{~mm})$ was significantly higher $(p=$ $0.0005, t$ test $)$ on the trained $(122.4 \pm 28.7)$ than the nontrained $(84.3 \pm 37.1)$ side.
A 3-D reconstruction of the ventral spinal cord at L6-L7 illustrates the differences in $\mathrm{GAD}_{67}$ distribution between the trained and nontrained sides (Fig. 5A). Reconstructed transverse views show that $\mathrm{GAD}_{67}$ levels vary with neuron size and location (Fig. $5 B-G$ ). On the trained side, punctate immunostaining was mostly on and around somata of large neurons. Neurons with cross-sectional areas between 1000 and $3000 \mu \mathrm{m}^{2}$ had a 4.7-fold higher mean $\mathrm{GAD}_{67}$ level on the trained than the nontrained side. Smaller neurons with cross-sectional areas ranging from 100 to $1000 \mu \mathrm{m}^{2}$ showed a smaller (1.4-fold) difference between sides.

A series of spinal cord sections corresponding to those analyzed for $\mathrm{GAD}_{67}$ were processed for $\mathrm{GAD}_{65}$. In contrast to the striking changes in $\mathrm{GAD}_{67}$ levels, $\mathrm{GAD}_{65}$ immunostaining did not differ in intensity or pattern between the trained and nontrained sides of the unilaterally stand-trained cats (data not shown). $\mathrm{GAD}_{65}$ expression was scattered randomly throughout the ventral horn on both the trained and nontrained sides. 

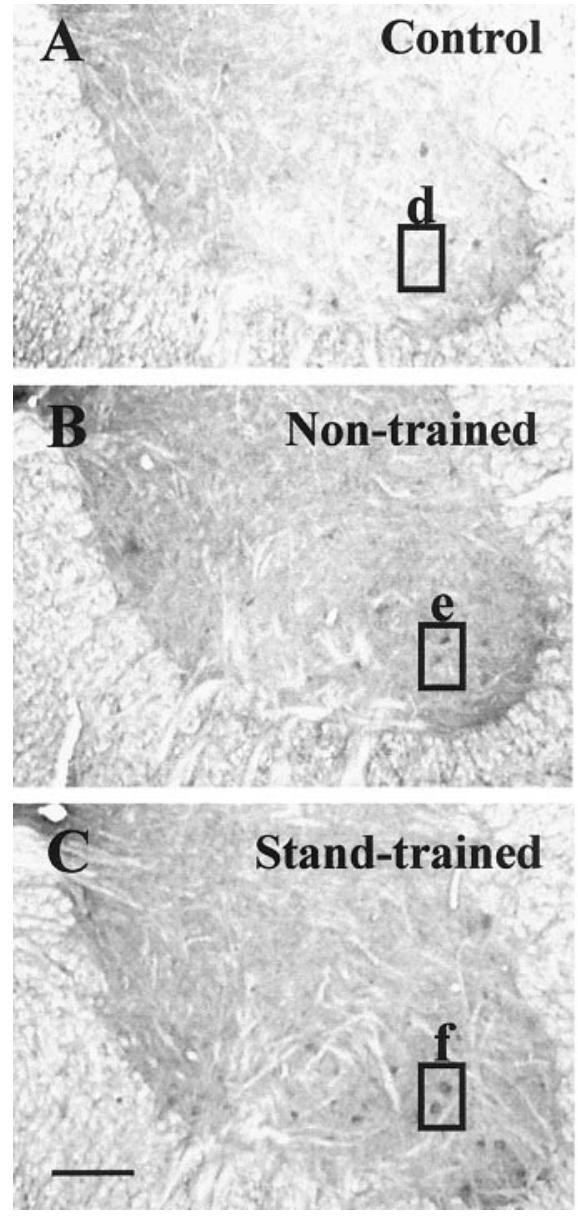
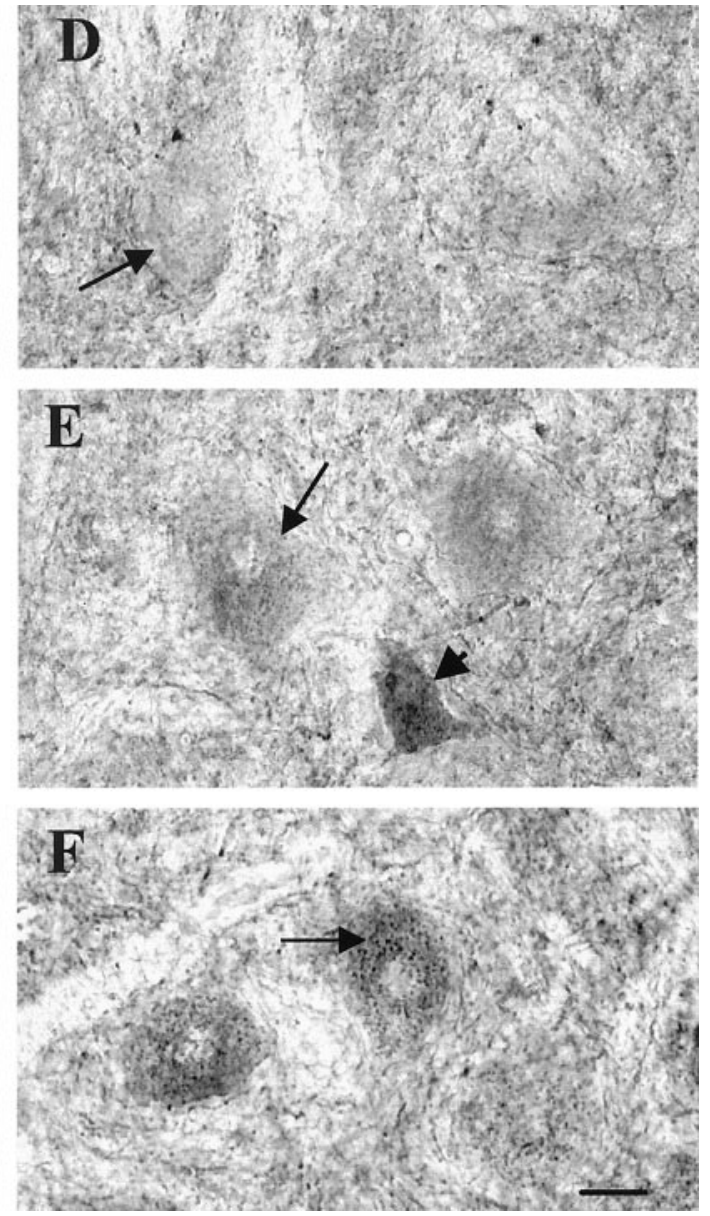

Figure 2. Bilateral stand training of spinal cats results in increased $\mathrm{GAD}_{67}$ immunoreactivity in a subset of neurons within lamina IX. Transverse sections of the L6 segment of the cat spinal cord were immunolabeled with an antibody to $\mathrm{GAD}_{67}$ (1: 4000). Compared with control cats $(A, D)$, chronic spinal cats $(B, E, C, F)$ have increased $\mathrm{GAD}_{67}$ immunoreactivity in neurons in lamina IX. Nontrained transected cats $(B, E)$ have neurons with stronger diff use $\mathrm{GAD}_{67}$ staining (E, arrowhead) as well as neurons with higher punctate staining $(E$, arrow) on the cell soma than control cats. Stand-trained transected cats $(C$, $F$ ) showed intense puncta on and around the soma of some neurons ( $F$, arrow). $A-C$, $\mathrm{GAD}_{67}$ immunoreactivity in the ventral horn; $D-F, \mathrm{GAD}_{67}$ immunoreactivity in lamina IX neurons (high-power view of insets in $A-C$, respectively). $A, D$, Control; $B, E, 25$ months after spinal transection, nontrained for 10 months; $C, F, 18$ months after spinal transection, trained 12 months to stand bilaterally. Scale bars: $A-C, 500$ $\mu \mathrm{m} ; D-F, 25 \mu \mathrm{m}$.

\section{Lack of asymmetry of $G_{A D}$ mRNAs expression in lamina IX neurons of unilaterally stand-trained cats suggests that the asymmetry of $\mathrm{GAD}_{67}$ immunoreactivity is in GABAergic interneurons}

To examine the regulation of $\mathrm{GAD}_{67}$ at the mRNA level, we used in situ hybridization to a digoxigenin-labeled riboprobe. $\mathrm{GAD}_{67}$ mRNA expression in lamina IX is low on both sides (Fig. 6, compare $E, F$ ). The pattern of $\mathrm{GAD}_{67}$ mRNA staining in the ventrolateral region of the trained side (Fig. 6D,F) does not reflect the asymmetry of the $\mathrm{GAD}_{67}$ immunoreactivity (Figs. 3-5). Instead, the most intensely labeled neurons (Fig. 6C,D, small arrows) were in the ventromedial region (lamina V II) on both the trained and nontrained sides.

\section{Bilateral step or stand training alters GAD $_{67}$ mRNA expression in ventral and dorsal horn neurons}

The GAD 67 levels in specific sets of neurons in both the ventral (Fig. 7) and dorsal (Fig. 8) horns were higher in transected than intact cats. Step or stand training lowered the $\mathrm{GAD}_{67} \mathrm{mRNA}$ in both regions (Figs. $7 B, D, 8 B, D$ ). The $\mathrm{GAD}_{67}$ mRNA levels were compared between the medial and lateral regions of the ventral horn of the four groups of cats. The levels of $\mathrm{GAD}_{67}$ (control, $0.21 \pm 0.01$; spinal nontrained, $0.33 \pm 0.01$; spinal step-trained, $0.28 \pm 0.01$; and spinal stand-trained, $0.30 \pm$ 0.01 ) in the ventromedial region were significantly different from each other ( $p<0.01$, mixed model analysis), except between the step-trained and the stand-trained groups ( $p=$ $0.07)$. In the ventrolateral region, only the $\mathrm{GAD}_{67}$ mRNA levels in the control group were significantly different from those of the nontrained group $(p<0.01$, mixed model analysis).

The number and level of staining of cells that were immunopositive for $\mathrm{GAD}_{67}$ mRNA in the medial (Fig. 9A) and lateral (Fig. 9B) regions of laminas $\mathrm{V}$ and VI (Fig. 9C) were determined. The highest number of positively stained cells and highest levels of $\mathrm{GAD}_{67}$ mRNA were observed in the nontrained followed by stand-trained, step-trained, and control cats. For the medial region, all experimental groups were significantly different from each other (Fig. $9 A ; p<0.05$ ). For the lateral region, the step-trained and intact groups were similar, but both were significantly lower than the stand-trained and nontrained cats (Fig. 9B; $p<0.05$ ).

\section{Reduced $\mathrm{GAD}_{67}$ protein levels in the lumbar spinal cord correlate with improved stepping ability}

Immunoblot analyses of L6 spinal cord homogenates of 12-month postspinal animals showed a negative correlation $(r=-0.84 ; p<$ 0.01 , mixed model analysis) between $\mathrm{GAD}_{67}$ levels and the performance of full weight-bearing stepping (Fig. 10). None of the nontrained animals could generate any weight-supported stepping, and all showed higher $\mathrm{GAD}_{67}$ levels than the step-trained animals. The integrated optical density of $\mathrm{GAD}_{67}$ immunoreactivity ranged from 4.1 to 10.8 arbitrary units in nontrained cats and from 1.2 to 3.3 arbitrary units in step-trained cats. These three cats were trained to step for only 1 week before termination. They had been trained previously to step for 2 months after spinal cord transection but had not been trained for the next 5 months. These data suggest that a significant reduction of $\mathrm{GAD}_{67}$ protein 
Non-trained side
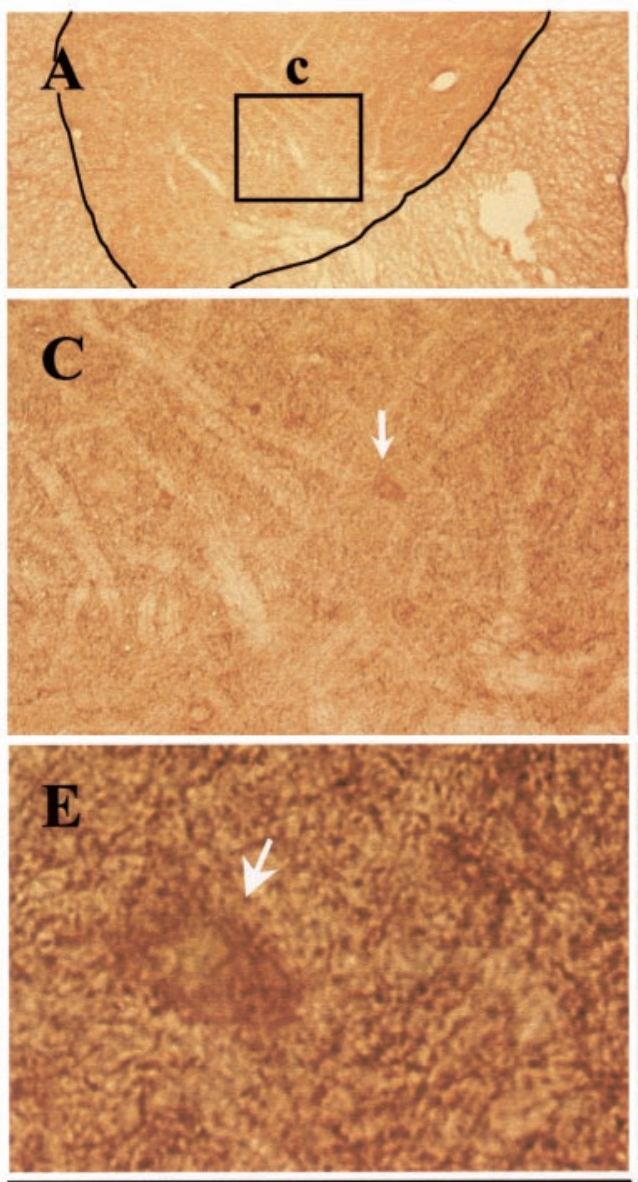

$\mathbf{G}$

VL
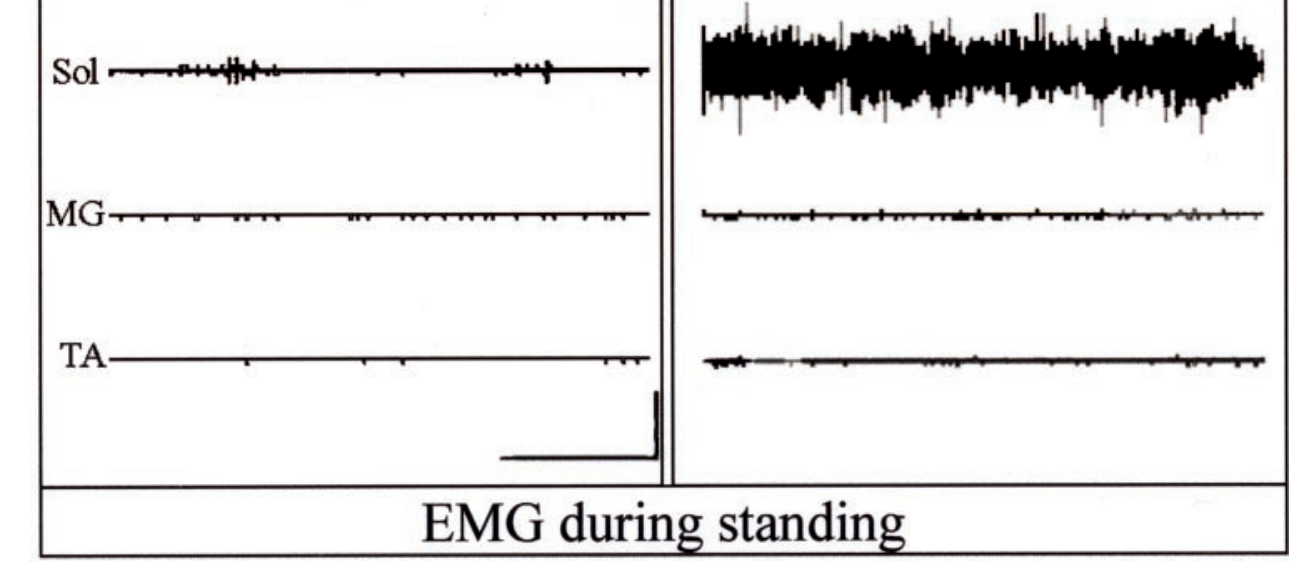

Figures 10 and 11 were constructed excluding the data corre-

\section{Trained side}
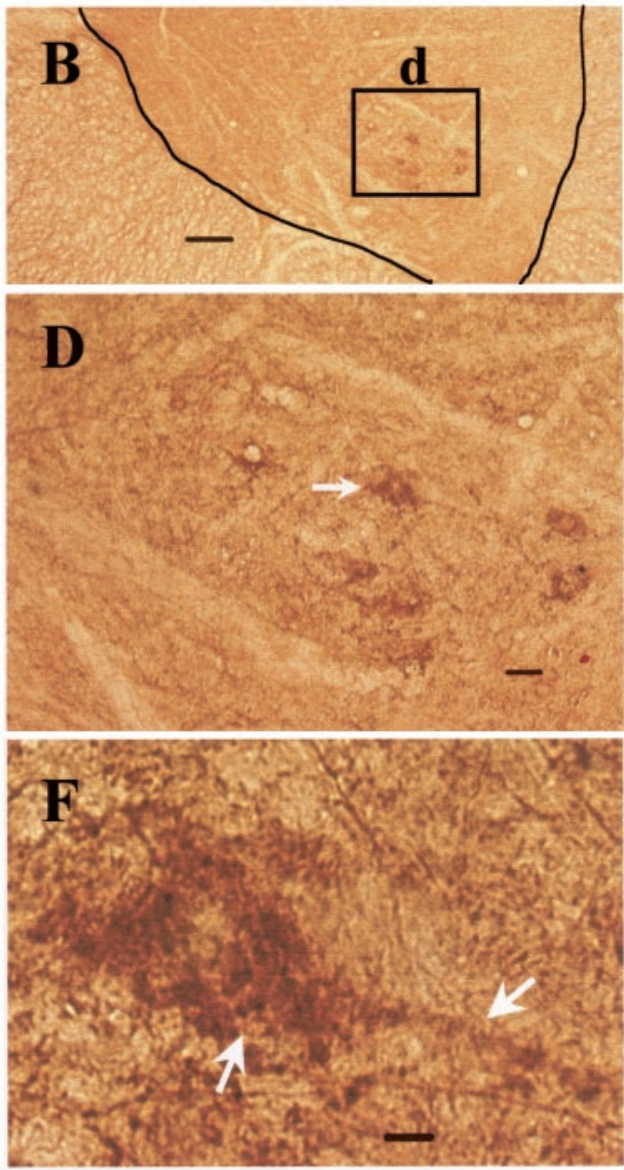

H
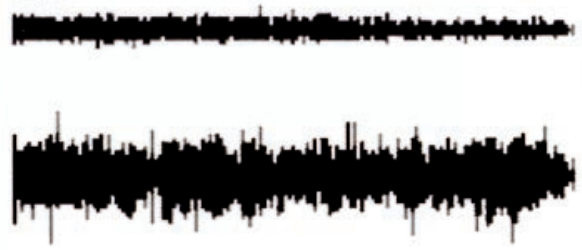
sponding to the worst steppers (less than five plantar steps/min). The GAD $_{67}$ levels at the $x$ intercepts were $\sim 200 \%$ of control. Thus, our estimates of $\mathrm{GAD}_{67}$ levels, from both slot blots (Fig. 10) and immunohistochemistry (Fig. 11), suggest a threshold of $\mathrm{GAD}_{67}$ above which the spinal animal cannot generate successful full weight-bearing stepping. If the optical density measures were $<200 \%$ of control levels, some stepping ability persisted.

We observed considerable differences among cats in $\mathrm{GAD}_{67}$

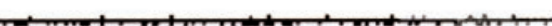
enlarged in $C$ and $D$. The neurons identi-
fied by arrows in $C$ and $D$ are enlarged in $E$ and $F$. Scale bars: $A, B, 200 \mu \mathrm{m} ; C, D, 50$ $\mu \mathrm{m} ; E, F, 10 \mu \mathrm{m}$. $G, H$, EMG activity patterns of hindlimb muscles of a unilaterally stand-trained cat during bilateral standing. There is higher EMG activity in the vastus lateralis $(V L)$ and soleus $(\mathrm{Sol})$ (extensor muscles) in the limb trained to stand than in the nontrained limb. $M G$, Medial gastrocnemius; $T A$, tibialis anterior. Calibration: $5 \mathrm{sec}, 2 \mathrm{mV}$.

can occur within 1 week of step retraining (control, $1.11 \pm 51$; nontrained, $5.86 \pm 0.57$; and step-trained, $2.14 \pm 0.66$; control vs nontrained and nontrained vs step-trained, $p<0.01$; control vs step-trained, $p=0.24$ ).

$\mathrm{GAD}_{67}$ protein levels in lamina IX neurons estimated by immunohistochemistry also showed an inverse correlation $(r=$ $-0.94 ; p<0.01$, mixed model analysis) between the $\mathrm{GAD}_{67}$ levels and the performance of full weight-bearing stepping 3-25 months after spinal cord transection (Fig. 11). The lines of best fit in 

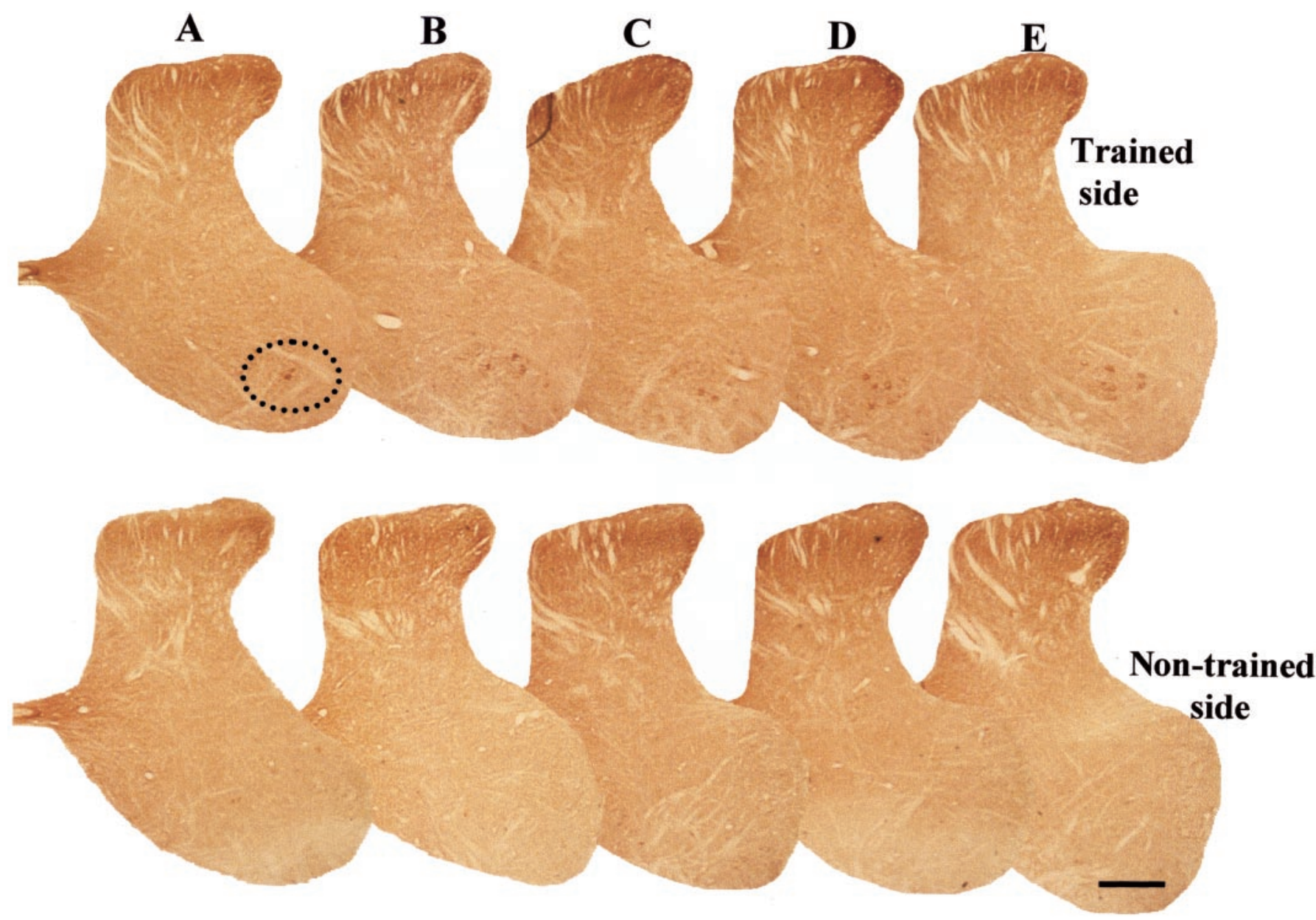

Figure 4. Asymmetric $\mathrm{GAD}_{67}$ immunoreactivity extends for at least $4 \mathrm{~mm}$ rostrocaudally. Sequential transverse sections (30- $\mu \mathrm{m}$-thick, $1: 4$ series) from spinal cord segments L6-L7 of a unilaterally stand-trained spinal cat immunolabeled for $\mathrm{GAD}_{67}$ are shown. Five representative sections $\sim 500 \mu \mathrm{m}$ apart are shown in sequential order rostrocaudally $(A-E)$. Ipsilateral sections (Trained side) are shown at the top, and the corresponding contralateral sections (Non-trained side) are shown at the bottom. Increased $\mathrm{GAD}_{67}$ immunoreactivity is limited to lamina IX (dotted area) neurons on the trained side. The distribution of highly labeled cells corresponds to the location of the semimembranosus and semitendinosus motor pools (Vanderhorst and Holstege, 1997). Scale bar, $500 \mu \mathrm{m}$.

levels in lamina IX. The differences in $\mathrm{GAD}_{67}$ could not be attributed to the duration of the period after transection or to the amount of training as much as to the quality of stepping at the time the animal was terminated. For example, of two step-trained cats examined 6 months after transection, the cat trained for 5 months (Fig. 1D) had more $\mathrm{GAD}_{67}$ staining than the cat trained for 3 months (data not shown). Furthermore, the staining in both of these animals was higher than that of a cat examined 25 months after transection and step-trained for the last 10 months (Fig. 1E).

The $\mathrm{GAD}_{67}$ levels can be associated with the regularity of EMG burst patterns during stepping, as shown in Figure $1 G-I$. For example, of the three trained animals shown in Figure 1, the animal with the highest $\mathrm{GAD}_{67}$ staining (Fig. $1 C$ ) had the most irregular EMG bursting pattern (Fig. 1I). Conversely, animals that showed regular EMG bursting patterns (Fig. 1G,H) had relatively low $\mathrm{GAD}_{67}$ staining (Fig. $1 D, E$ ). This association of regular EMG patterns and low $\mathrm{GAD}_{67}$ staining was observed in animals even 18-25 months after spinal cord transection (Fig. $1 E, H)$. In effect, these data show that those animals with the highest locomotor capacity have the lowest neuronal GAD $_{67}$ levels and the most regular EMG patterns during locomotion. Furthermore, these data demonstrate that these three variables can be readily modulated by specific motor training regimes in chronic spinal animals.

\section{DISCUSSION}

Hindlimb step training of spinally transected cats resulted in more weight-bearing steps performed on the plantar surface of the paw compared with nontrained spinal cats (de Leon et al., 1998a). Because the improved ability to step was not attributable to changes in the hindlimb muscle properties (Roy et al., 1991, 1998, 1999), the recovery must depend on changes within the lumbar spinal cord.

Our previous studies showed that spinally transected cats trained to maintain a standing posture have poor stepping ability. This inability to perform weight-supporting stepping is reflected in the generation of irregular and poorly coordinated EMG bursts in hindlimb extensor and flexor muscles (de Leon et al., 1999). These stand-trained animals, however, can quickly (within 40 min) generate full weight-bearing steps over a range of treadmill speeds after the administration of strychnine, i.e., a glycine receptor antagonist (de Leon et al., 1999). This observation is consistent with an increase in glycine receptor density after spinal cord transection of rats that are not trained, whereas the receptor 

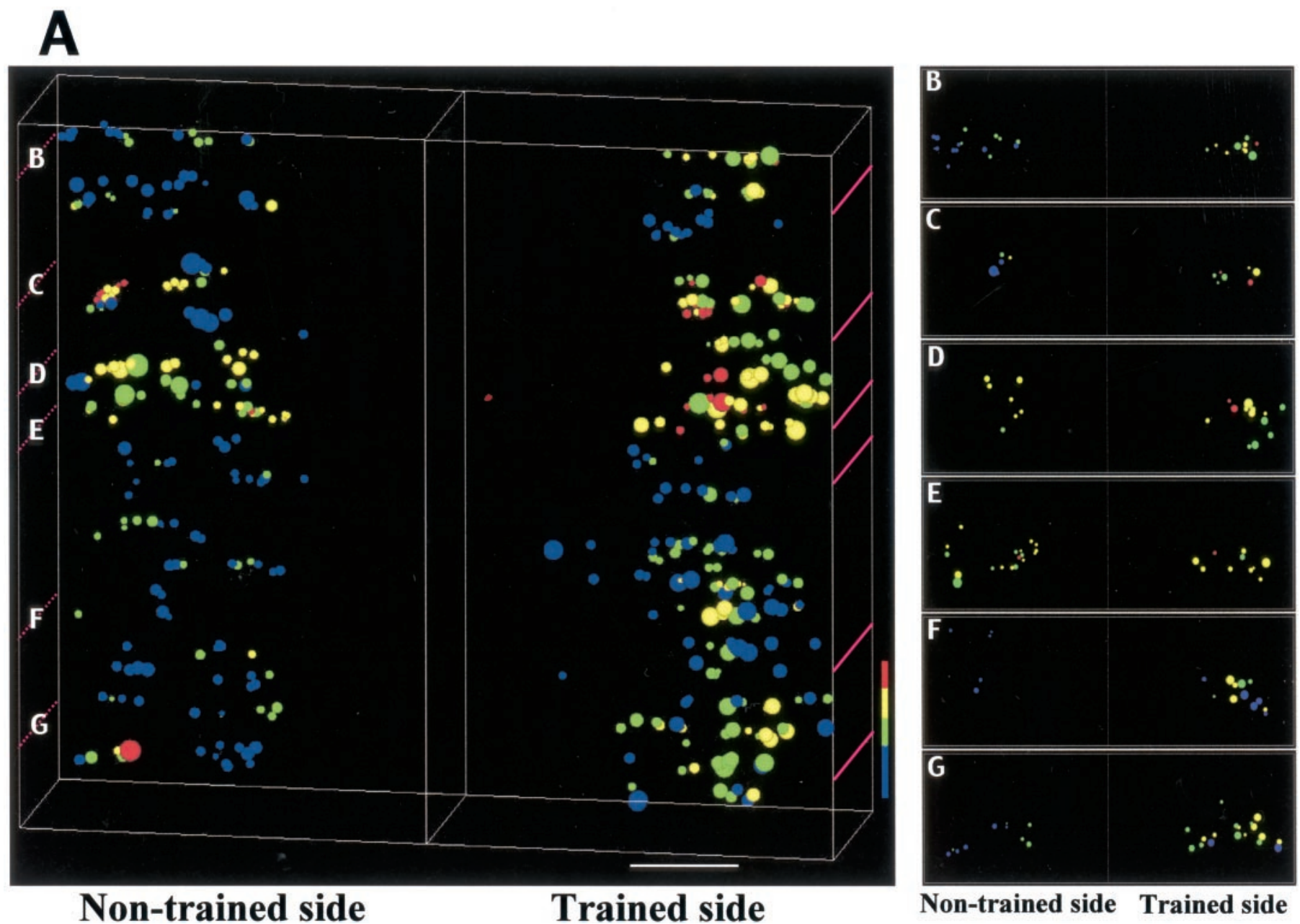

Non-trained side Trained side

Figure 5. 3-D reconstruction of $\mathrm{GAD}_{67}$ immunoreactivity in spinal cord sections from cats trained to stand unilaterally. The distribution of $\mathrm{GAD}_{67}$-immunoreactive neurons was determined from 25 sequential cross sections (30- $\mu$ m-thick) from the L6 and L7 spinal cord segments spanning $\sim 3$ $\mathrm{mm}(A)$. Sections stained for $\mathrm{GAD}_{67}$ were taken approximately every $120 \mu \mathrm{m}$. Individual $\mathrm{GAD}_{67}$-positive neurons in the ventral horn were captured at $500 \times$ at identical illumination. The area, the integrated optical density, and the corresponding $x, y$, and $z$ positional information of these neurons were used to construct a 3-D image of $\mathrm{GAD}_{67}$ immunostaining. Six of 25 spinal cord sections arranged rostrocaudally are shown in $B-G$ (top view). The level

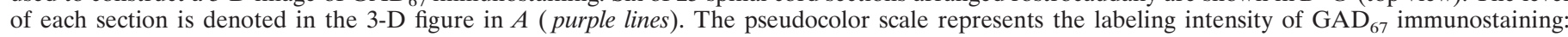
$1.00-0.80$, red; $0.79-0.60$, yellow; $0.59-0.40$, green; $<0.39$, blue. The distributions of neurons (spanning 3 mm) across the intensity ranges were statistically different between trained and nontrained sides $\left(p=0.02, \chi^{2}\right.$ test; total number of neurons $\left.=464\right)$. Scale bar, $500 \mu \mathrm{m}$.

density is normal in spinal rats trained to step (Edgerton et al., 2001). Combined, these data suggest a limitation in the normal capability to inhibit antagonist motor pools reciprocally during stepping in spinal animals that have been stand-trained or nontrained (Edgerton et al., 1997; de Leon et al., 1999). Because the reciprocal activity of antagonist motor pools depends on GABA and glycine as inhibitory neurotransmitters, they most likely play a central role in the generation of stepping and standing after spinal cord injury.

\section{Increased GABA signaling in the lumbar spinal cord may interfere with hindlimb stepping in spinal cats}

Our data show that stepping ability is inversely related to $\mathrm{GAD}_{67}$ levels in the lumbar spinal cord (Figs. 10, 11). Given the combination of experimental paradigms reported here, this relationship appears to be independent of the time after spinal cord transection (3-25 months). We hypothesized that the poor stepping ability observed after stand training results from selective enhancement of inhibitory pathways that project to flexor motor pools, e.g., the semimembranosus and semitendinosus (Fig. 12).
The absence of EMG activity observed in the semitendinosus during standing (Fig. 1) is consistent with this potential inhibitory effect, although no detectable EMG also could be interpreted as simply no activation of the motoneurons rather than direct inhibition. This specific inhibitory bias of flexor motor pools could contribute to the inability to step, although these animals could stand (Fig. 1) (Edgerton et al., 1991; de Leon et al., 1998b, 1999). Continuous stepping, which requires alternating activation of flexor and extensor sensorimotor pathways, in contrast, may result in a greater balance of inhibition and excitation of all motor pools that contribute to locomotion (Edgerton et al., 1997; de Leon et al., 1998b, 1999).

In unilaterally stand-trained, spinally transected cats, we found increases in $\mathrm{GAD}_{67}$ associated with specific lumbar neurons in the ventral horn of the trained side. On the basis of size, shape, and position, most of these neurons were likely semimembranosus and semitendinosus motoneurons (Vanderhorst and Holstege, 1997). Unequivocal identification of flexor or extensor motoneurons, however, will require labeling with retrogradely transported 


\section{Non-trained side}
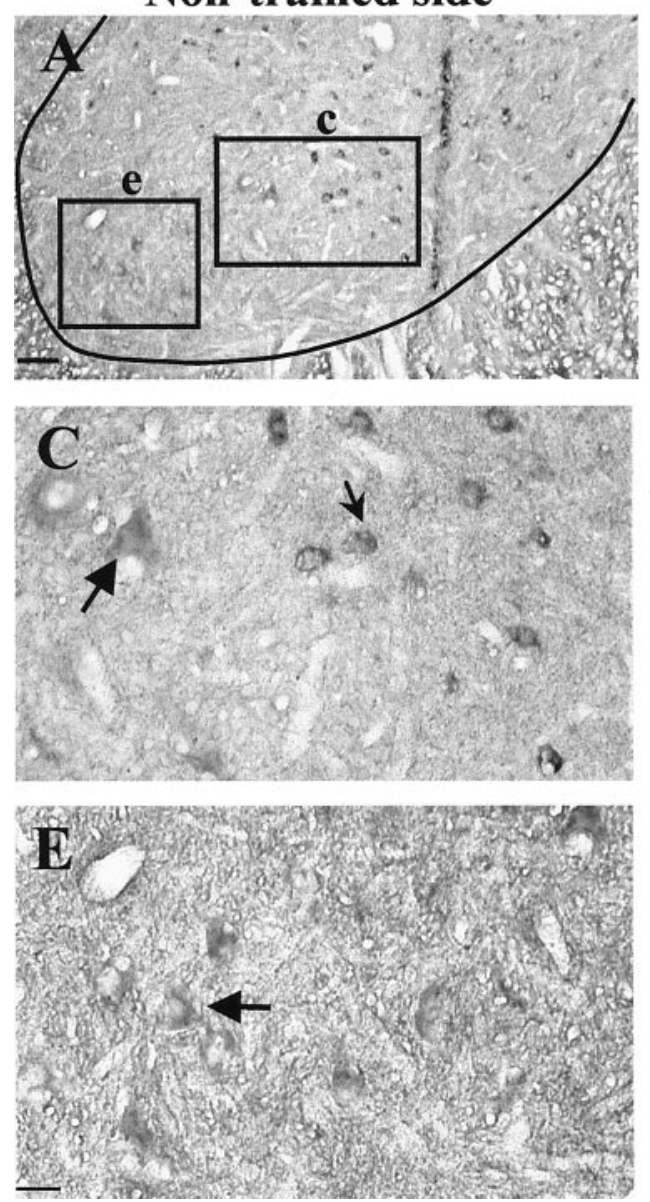

Trained side
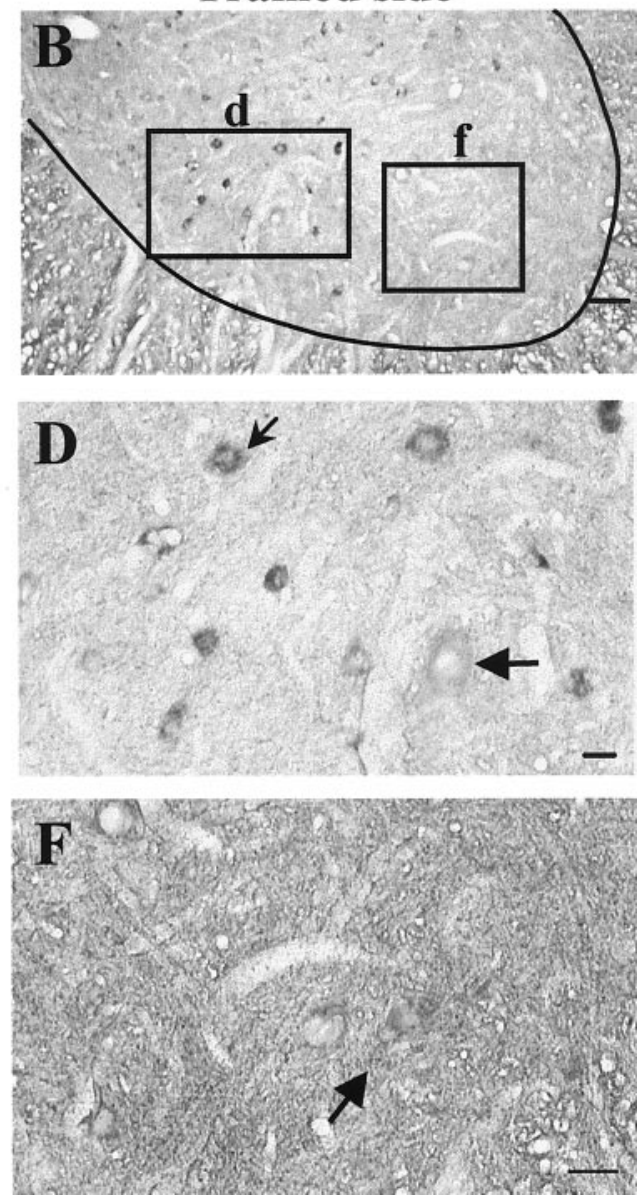

Figure 6. Unilateral stand training does not result in an asymmetrical increase in $\mathrm{GAD}_{67}$ mRNA in the L6 and L7 ventral horn. In situ hybridization to $\mathrm{GAD}_{67}$ mRNA in the ventral horn of a transected cat trained to stand unilaterally for 3 months was performed. $A, B$, Comparison of the distribution of $\mathrm{GAD}_{67}$ mRNA in the L6 ventral horn on the nontrained $(A)$ and trained $(B)$ sides. Ventromedial neurons (insets $c, d$ in $A, B$, respectively) and ventrolateral neurons (insets $e, f$ in $A, B$, respectively) are shown at high magnification in $C, D$ and $E, F$, respectively. Small arrows show intensely labeled neurons in lamina VII, and large arrows show weakly labeled arrows in lamina IX. Scale bars: $A$, $B, 100 \mu \mathrm{m} ; D, 25 \mu \mathrm{m} ; E, F, 50 \mu \mathrm{m}$.

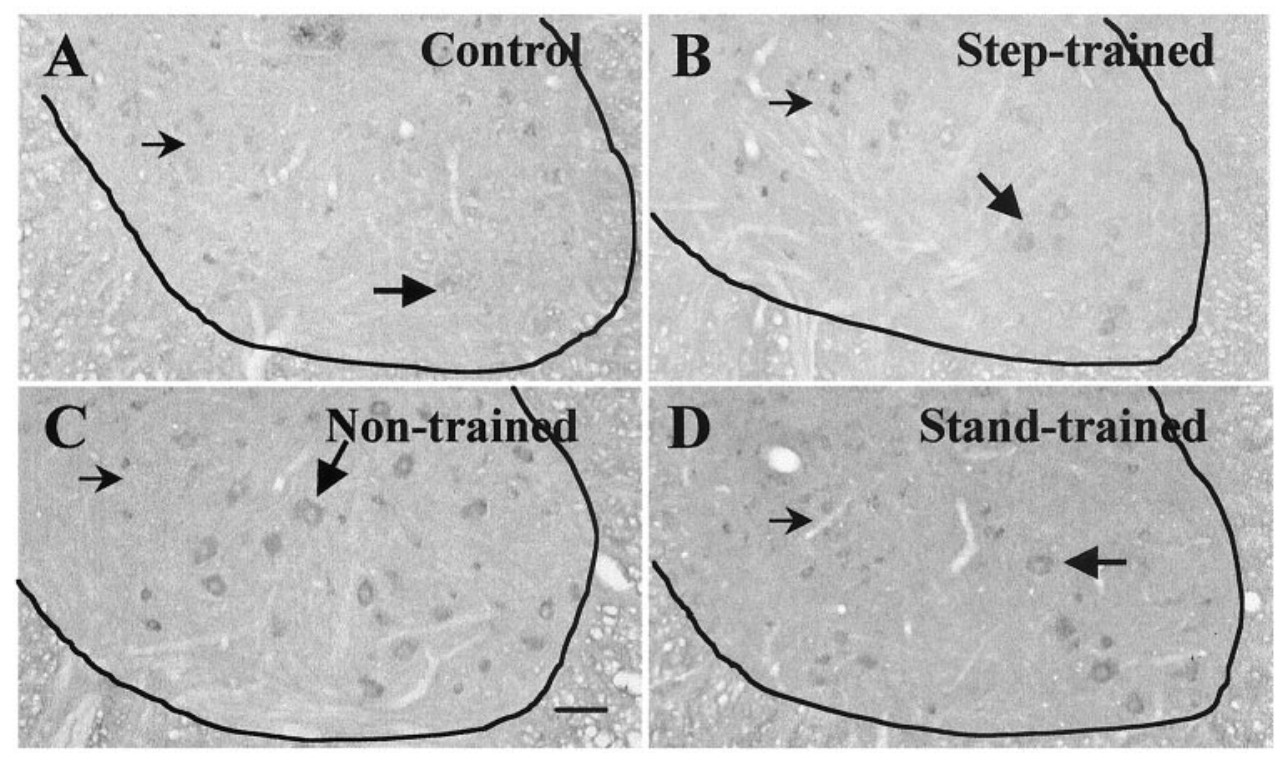

Figure 7. Step training decreases transection-induced $\mathrm{GAD}_{67}$ mRNA levels in the ventral horn. In situ hybridization to $\mathrm{GAD}_{67}$ mRNA in the ventral horn of the L6 segment of the lumbar spinal cord was performed. $\mathrm{GAD}_{67}$ mRNA levels are higher in 6 month-transected $(B-D)$ than control $(A)$ cats. Labeled cells include large neurons (large arrows) as well as small neurons (small arrows) in the medial and lateral regions of the ventral horn. The numbers of positively stained cells are divided into lower $(<0.3)$ and higher $(\geq 0.3)$ optical density levels. Group differences in the number of positive cells occurred at the higher optical densities (Control, 0\%; Non-trained, 88\%; Standtrained, $53 \%$; Step-trained, $39 \% ; p<0.01$ ). $A$, Control; $B, 6$ months after transection, trained to step bilaterally for 3 months; $C$, 6 months after transection, nontrained; $D$, 6 months after transection, trained to stand bilaterally for 3 months. Scale bar, $100 \mu \mathrm{m}$.

markers. To what extent this differential $\mathrm{GAD}_{67}$ staining reflects training-enhanced excitability of extensors, training-enhanced inhibition of flexors, or both also remains to be determined.

Given that there was no retrograde labeling of motoneurons, we cannot be certain that all labeled cells were motoneurons.
However, the cells with increased $\mathrm{GAD}_{67}$ immunoreactivity are unlikely to be Renshaw cells, because Renshaw cells in the cat are located mainly in ventral lamina V II and only rarely in lamina IX (Fyffe, 1990). Furthermore, cells containing GAD $_{67}$ mRNA were not evident in lamina IX. The apparent absence of $\mathrm{GAD}_{67}$ 

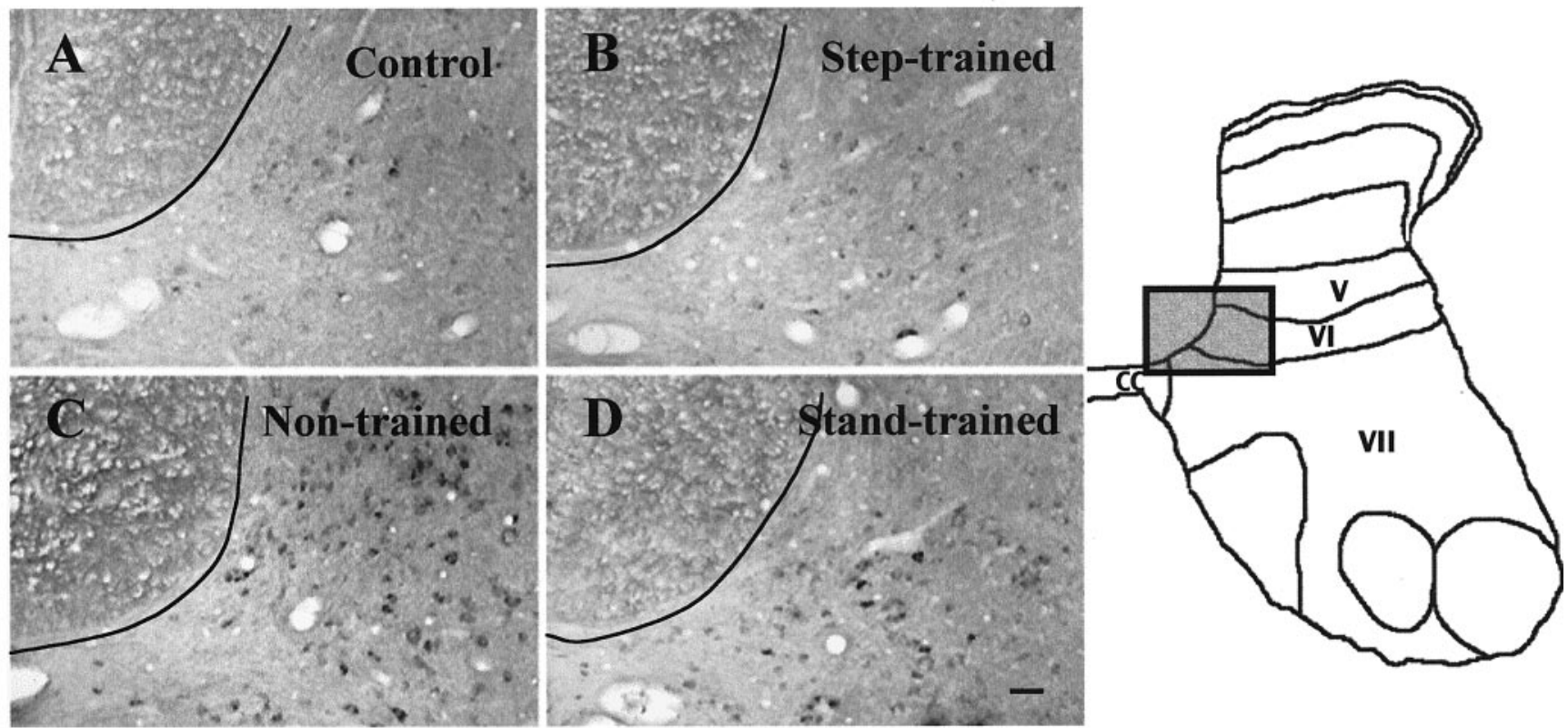

Figure 8. Training modulates $\mathrm{GAD}_{67}$ mRNA levels in specific neuronal populations in medial laminas V and V I. In situ hybridization to GAD 67 mRNA in medial laminas V and VI of L6 spinal cord segments was performed. Compared with control cats $(A)$, the number of labeled neurons and the intensity of labeling are highest in the spinal cords of nontrained spinal cats $(C)$, with progressively fewer labeled cells and less staining in stand-trained $(D)$ and step-trained $(B)$ spinal cats. $A$, Control; $B, 6$ months after transection, trained to step for 5 months; $C, 6$ months after transection, nontrained; $D, 6$ months after transection, trained to stand bilaterally for 5 months. $E$, The shaded area in the spinal cord template shows the area magnified in $A-D$. $C C, C$ entral canal. Scale bar, $50 \mu \mathrm{m}$.

Figure 9. Training modulates $\mathrm{GAD}_{67}$ mRNA levels in the medial and lateral portions of laminas $\mathrm{V}$ and VI. GAD $_{67}$ mRNA levels are elevated in the medial $(A)$ and lateral $(B)$ portions of spinal cord laminas $\mathrm{V}$ and VI (area in $C$ ) in L6 and L7 segments 6 months after spinalization. Differences in the mean optical densities were significant among all groups in the medial portion ( $p<0.05$, boot-strapping analysis). In the lateral portion, the mean optical densities in the nontrained and stand-trained groups were significantly different $(p<0.05$, boot-strapping analysis; number of animals in each group $=2$ ) from the step-trained and intact groups. The number of positively stained cells are divided into lower (0.2-0.3) and higher (0.3-0.4) optical density levels. Group differences in the number of positive cells occurred in the higher optical densities $(p<0.05)$.
A Medial laminae V-VI

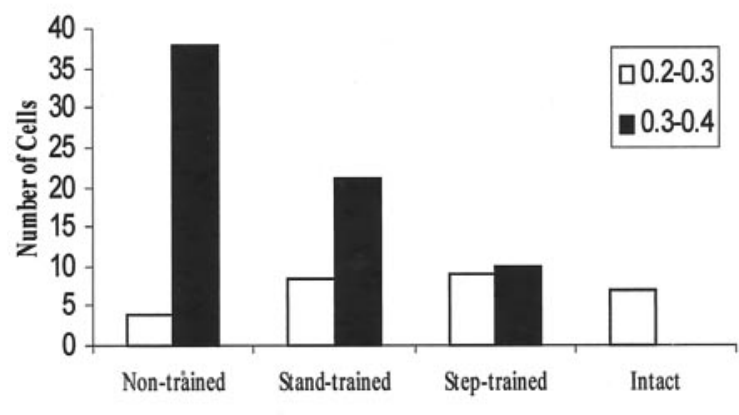

B

Lateral laminae V-VI

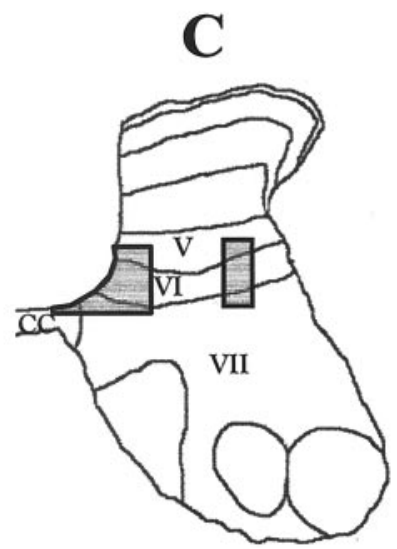

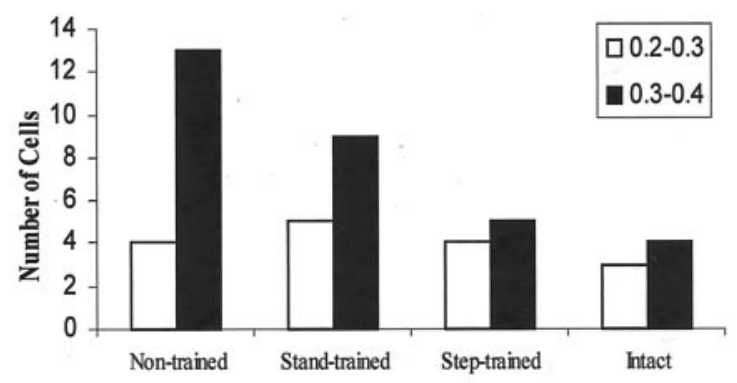




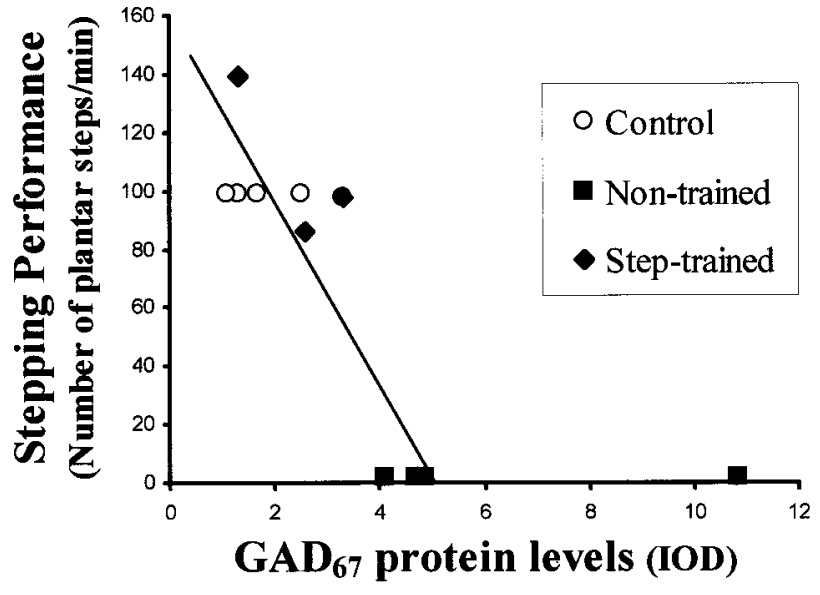

Figure 10. $\mathrm{GAD}_{67}$ levels in the lumbar spinal cord are inversely related to the stepping ability of spinal cats. The relationship between the mean $\mathrm{GAD}_{67}$ protein levels in spinal cord extracts and the stepping ability of control and spinal-transected cats 12 months after transection is shown. The highest $\mathrm{GAD}_{67}$ protein levels were observed in the animals with the poorest stepping ability. Step-trained animals had lower $\mathrm{GAD}_{67}$ protein levels than nontrained cats but higher levels than control cats. The data points represent the mean integrated optical density $(I O D)$ of $\mathrm{GAD}_{67^{-}}$ immunopositive bands determined from L6 spinal cord segments using slot blots. The line of best fit excludes the animal with the highest $\mathrm{GAD}_{67}$ level. The regression equation is $y=-31.54 x+158.8 ; r=-0.89 ; p<$ 0.01 .

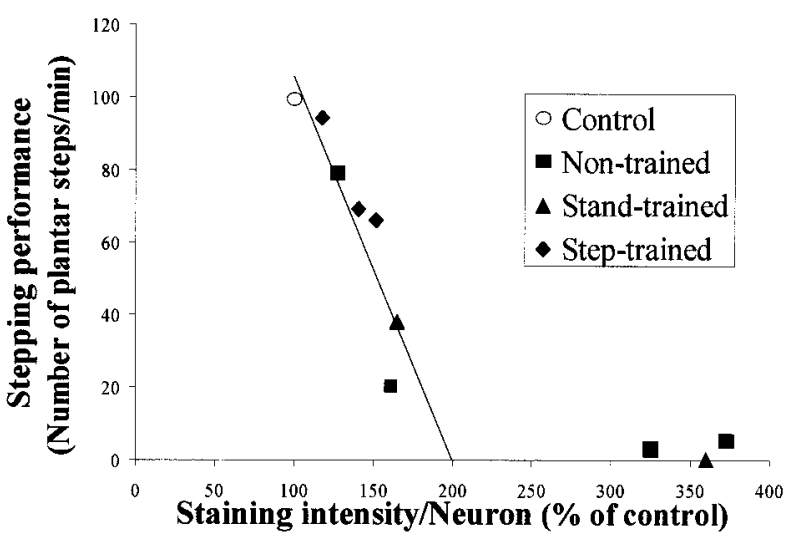

Figure 11. Reduced $\mathrm{GAD}_{67}$ immunoreactivity levels around lamina IX neurons correlate with improved stepping ability. The relationship between the mean $\mathrm{GAD}_{67}$ immunoreactivity of lamina IX neurons and the stepping ability of control and spinal-transected cats is shown. The highest $\mathrm{GAD}_{67}$ immunoreactivity levels were observed in the animals with the poorest stepping ability. Control animals showed the least $\mathrm{GAD}_{67}$ immunoreactivity. Each data point represents the mean optical density determined from individual measurements of 120 neurons within the L6 spinal cord segment of each animal expressed as a percentage of control. The line of best fit excludes the animals with $\mathrm{GAD}_{67}$ levels exceeding $200 \%$ of the values of control cats. The regression equation is $y=-1.1 x+210 ; r=$ $-0.94 ; p<0.01$.

mRNA in these neurons further suggests that these cells are motoneurons receiving $\mathrm{GAD}_{67}$ inputs rather than Renshaw cells or Ia inhibitory interneurons that synthesize $\mathrm{GAD}_{67}$. Both of these neuronal types synapse on motoneurons, with Renshaw cells terminating predominantly on motoneuron dendrites and more Ia inhibitory neurons projecting on motoneuron somata (Burke et al., 1971; Fyffe, 1991). Because we quantified the $\mathrm{GAD}_{67}$ in cell somata only, the observed increased inhibitory

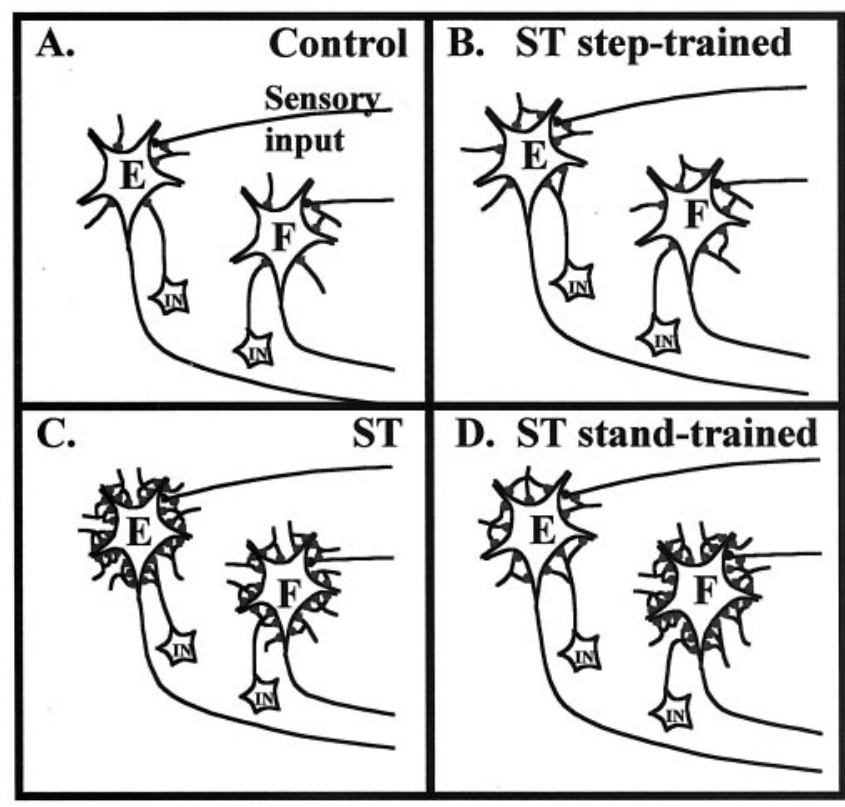

Figure 12. Schematic illustrating our underlying hypothesis. The relative density of inhibitory synapses around flexor and extensor motoneurons for control $(A)$, spinal-transected, step-trained $(B)$, spinal-transected, nontrained $(C)$, and spinal-transected, stand-trained $(D)$ animals is illustrated. The puncta on motoneurons are inhibitory inputs from interneurons $(I N)$ and represent specific states of inhibitory signaling in the spinal cord. The motoneurons are shown to receive homonymous excitatory input and input from an Ia interneuron driven by its antagonist. The data shown in this study are consistent with the hypothesis that in the control animal, inhibitory inputs to both flexor $(F)$ and extensor $(E)$ neurons are modest $(A)$, whereas spinal transection results in a marked increase in inhibitory inputs to both flexor and extensor motoneurons. Step training $(B)$ results in a reversion to a more normal level of inhibitory input to both extensor and flexor motoneurons. In stand-trained animals $(D)$, a relatively high level of inhibitory inputs is sustained to flexor motoneurons, whereas extensor motoneurons have slightly less inhibitory input compared with nontrained animals $(C)$. Because of the chronic absence of weight-bearing and, therefore, extensor activity in spinal-transected, nontrained animals $(B)$, we further hypothesize that the level of inhibitory input to the extensor motoneurons will exceed that observed for the flexor motoneurons.

capacity may reflect more reciprocal than recurrent inhibition (Fyffe, 1991). On the other hand, other unidentified types of inhibitory interneurons could contribute to the enhanced $\mathrm{GAD}_{67}$ observed on the cell bodies of these neurons.

\section{Changes in $\mathrm{GAD}_{67}$ levels in the spinal cord seem to be} modulated by afferent input

Certainly the sensory information projecting to the spinal cord in nontrained, step-trained, and stand-trained transected animals differ from each other and from intact cats because of variations in their weight-bearing, postural, and cutaneous activation levels. Furthermore, with the synaptic reorganization that occurs after spinal cord injury, the interpretation of a given sensory input to the spinal cord of a spinal cord-injured animal may differ substantially from that of an intact animal (Nacimiento et al., 1995; Tai et al., 1997). Changes in sensory input may affect GABA signaling by modulating $\mathrm{GAD}_{67}$ in spinal interneurons. For example, we found changes in $\mathrm{GAD}_{67}$ neurons in some areas known to contain primary afferent terminals from the hindlimb muscles, i.e., the medial and lateral regions of laminas IV-VI and the ventral horn (Brown, 1981). The number of neurons containing $\mathrm{GAD}_{67}$ mRNA and the levels of $\mathrm{GAD}_{67}$ mRNA in laminas $\mathrm{V}$ and 
VI are higher in nontrained and stand-trained than in steptrained spinal cats (Fig. 9). Elimination of sensory inputs to the spinal cord after lumbar dorsal rhizotomy also induces a large increase in the number of neurons containing $\mathrm{GAD}_{67}$ mRNA and an increase in $\mathrm{GAD}_{67}$ in all regions of the rat spinal cord where afferent terminals would normally be present, including the ventral horn (Dumoulin et al., 1996).

Pharmacological data also are consistent with increased GABA signaling interfering with hindlimb stepping in spinal cats. For example, the stepping ability of poorly stepping spinal cats can be dramatically improved with administration of the $\mathrm{GABA}_{\mathrm{A}}$ receptor antagonist bicuculline (Robinson and Goldberger, 1986; Edgerton et al., 1997). In a previous study, we initially observed a short period of spasticity followed by occasional alternating hindlimb movement on bicuculline administration (Edgerton et al., 1997). By $8 \mathrm{~min}$, the stepping progressed to near full weight bearing on the plantar surfaces of the paws. These effects decayed by $15 \mathrm{~min}$, reverting to the predrug pattern of stepping. Modest doses of strychnine, which did not affect locomotion in steptrained cats, significantly improved the stepping ability of poorly stepping nontrained and stand-trained cats (de Leon et al., 1999). All these data suggest that the spinal cords of stand-trained and nontrained cats have some similarities; i.e., both have a selectively higher inhibitory potential in specific neural pathways compared with step-trained animals. The improvement of stepping with the administration of bicuculline and strychnine may occur by overcoming abnormally high levels of general inhibition of extensor motor pools in nontrained or in flexor motor pools in standtrained cats (Fig. 12).

These data are consistent with the hypothesis that $\mathrm{GAD}_{67}$ plays an important role in defining the inhibitory capacity of specific groups of neurons. The ability of spinal cats to step and stand may be a result of its regulated synthesis of GABA, which in turn serves to modulate the relative excitation in the appropriate motor pools in temporally appropriate patterns for successful weight-bearing stepping or standing. This regulation of potential GABA synthesis is clearly activity-dependent and limited to those neuronal systems that directly contribute to the execution of a given motor task.

\section{REFERENCES}

Barbeau H, Rossignol S (1987) Recovery of locomotion after chronic spinalization in the adult cat. Brain Res 412:84-95.

Brown AG (1981) Organization in the spinal cord: the anatomy and physiology of identified neurons. Berlin: Springer.

Buerger AA, Fennessy A (1971) Long-term alteration of leg position due to shock avoidance by spinal rats. Exp Neurol 30:195-211.

Burke RE, Fedina L, Lundberg A (1971) Spatial synaptic distribution of recurrent and group Ia inhibitory systems in cat spinal motoneurones. J Physiol (Lond) 214:305-326.

Chang YC, Gottlieb DI (1988) Characterization of the proteins purified with monoclonal antibodies to glutamic acid decarboxylase. J Neurosci 8:2123-2130.

Chen XY, Wolpaw JR (1995) Operant conditioning of H-reflex in freely moving rats. J Neurophysiol 73:411-415.

Chen XY, Wolpaw JR (1997) Dorsal column but not lateral column transection prevents down-conditioning of $\mathrm{H}$ reflex in rats. J Neurophysiol 78:1730-1734.

Chen XY, Wolpaw JR, Jakeman LB, Stokes BT (1999) Operant conditioning of $\mathrm{H}$-reflex increase in spinal cord-injured rats. J Neurotrauma 16:175-186.

de Guzman CP, Roy RR, Hodgson JA, Edgerton VR (1991) Coordination of motor pools controlling the ankle musculature in adult spinal cats during treadmill walking. Brain Res 555:202-214.

de Leon RD, Hodgson JA, Roy RR, Edgerton VR (1994) Extensor- and flexor-like modulation within motor pools of the rat hindlimb during treadmill locomotion and swimming. Brain Res 654:241-250.

de Leon RD, Hodgson JA, Roy RR, Edgerton VR (1998a) Locomotor capacity attributable to step training versus spontaneous recovery after spinalization in adult cats. J Neurophysiol 79:1329-1340.

de Leon RD, Hodgson JA, Roy RR, Edgerton VR (1998b) Full weightbearing hindlimb standing following stand training in the adult spinal cat. J Neurophysiol 80:83-91.

de Leon RD, Tamaki H, Hodgson JA, Roy RR, Edgerton VR (1999) Hindlimb locomotor and postural training modulates glycinergic inhibition in the spinal cord of the adult spinal cat. J Neurophysiol 82:359-369.

Dumoulin A, Alonso G, Privat A, Feldblum S (1996) Biphasic response of spinal GABergic neurons after a lumbar rhizotomy in the adult rat. Eur J Neurosci 8:2553-2563.

Edgerton VR, de Guzman CP, Gregor RJ, Roy RR, Hodgson JA, Lovely RG (1991) Trainability of the spinal cord to generate hindlimb stepping patterns in adult spinalized cats. In: Neurobiological basis of human locomotion (Shimamura M, Grillner S, Edgerton VR, eds), pp 411-423. Tokyo: Japan Scientific Societies.

Edgerton VR, de Leon RD, Tillakaratne NJK, Recktenwald MR, Hodgson JA, Roy RR (1997) Use-Dependent plasticity in spinal stepping and standing. Adv Neurol 72:233-247.

Edgerton VR, de Leon RD, Tillakaratne NJK, Hodgson JA (1998) Does motor learning occur in the spinal cord? Neuroscientist 3:287-294.

Edgerton VR, de Leon RD, Harkema SJ, Hodgson JA, London N, Reinkensmeyer DJ, Roy RR, Talmadge RJ, Tillakaratne NJK, Timoszyk W, Tobin AJ (2001) Retraining the injured spinal cord. J Physiol (Lond) 533:15-22.

Efron B, Tibshirani RJ (1993) An introduction to the boot strap. New York: Chapman and Hall.

Erlander MG, Tillakaratne NJ, Feldblum S, Patel N, Tobin AJ (1991) Two genes encode distinct glutamate decarboxylases. Neuron 7:91-100. Esclapez M, Tillakaratne NJ, Tobin AJ, Houser CR (1993) Comparative localization of mRNAs encoding two forms of glutamic acid decarboxylase with nonradioactive in situ hybridization methods. J Comp Neurol 331:339-362.

Esclapez M, Tillakaratne NJ, Kaufman DL, Tobin AJ, Houser CR (1994) Comparative localization of two forms of glutamic acid decarboxylase and their mRNAs in rat brain supports the concept of functional differences between the forms. J Neurosci 14:1834-1855.

Fengchen KC, Wolpaw JR (1996) Operant conditioning of H-reflex changes synaptic terminals on primate motoneurons. Proc Natl Acad Sci USA 93:9206-9211.

Fyffe RE (1990) Evidence for separate morphological classes of Renshaw cells in the cat's spinal cord. Brain Res 536:301-304.

Fyffe RE (1991) Spatial distribution of recurrent inhibitory synapses on spinal motoneurons in the cat. J Neurophysiol 65:1134-1149.

Grau JW, Barstow DG, Joynes RL (1998) Instrumental learning within the spinal cord: I. Behavioral properties. Behav Neurosci 112:1366-1386.

Kaufman DL, McGinnis JF, Krieger NR, Tobin AJ (1986) Brain glutamate decarboxylase cloned in lambda gt-11: fusion protein produces gamma-aminobutyric acid. Science 232:1138-1140.

Kaufman DL, Houser CR, Tobin AJ (1991) Two forms of the gammaaminobutyric acid synthetic enzyme glutamate decarboxylase have distinct intraneuronal distributions and cofactor interactions. J Neurochem 56:720-723.

Kluver H, Barrera E (1953) A method for the combined staining of cells and fibers in the nervous system. J Neuropathol Exp Neurol $12: 400-403$.

Lovely RG, Gregor RJ, Roy RR, Edgerton VR (1986) Effects of training on the recovery of full-weight-bearing stepping in the adult spinal cat Exp Neurol 92:421-435.

Lovely RG, Gregor RJ, Roy RR, Edgerton VR (1990) Weight-bearing hindlimb stepping in treadmill-exercised adult spinal cats. Brain Res 514:206-218.

Nacimiento W, Sappok T, Brook GA, Toth L, Schoen SW, Noth J, Kreutzberg GW (1995) Structural changes of caudal to a low thoracic spinal cord hemisection in the adult rat: a light and electron microscopic study. Acta Neuropathol (Berl) 90:552-564.

Pierotti DJ, Roy RR, Gregor RJ, Edgerton VR (1989) Electromyographic activity of cat hindlimb flexors and extensors during locomotion at varying speeds and inclines. Brain Res 41:57-66.

Robinson GA, Goldberger ME (1986) The development and recovery of motor function in spinal cats. II. Pharmacological enhancement of recovery. Exp Brain Res 62:387-400.

Roy RR, Acosta L (1986) Fiber type and fiber size changes in selected thigh muscles six months after low thoracic spinal cord transection in adult cats: exercise effects. Exp Neurol 92:675-685.

Roy RR, Baldwin KM, Edgerton VR (1991) The plasticity of skeletal muscle: effects of neuromuscular activity. Exerc Sport Sci Rev 19:269-312.

Roy RR, Hodgson JA, Lauretz SD, Pierotti DJ, Gayek RJ, Edgerton VR (1992) Chronic spinal cord-injured cats: surgical procedures and management. Lab Anim Sci 42:335-343.

Roy RR, Talmadge RJ, Hodgson JA, Zhong H, Baldwin KM, Edgerton VR (1998) Training effects on soleus of cats spinal cord transected (T12-13) as adults. Muscle Nerve 21:63-71. 
Roy RR, Talmadge RJ, Hodgson JA, Oishi Y, Baldwin KM, Edgerton VR (1999) Differential response of fast hindlimb extensor and flexor muscles to exercise in cats spinalized as adults. Muscle Nerve 22:230241.

Steinmetz JE, Cervenka J, Robinson C, Romano AG, Patterson MM (1981) Fixation of spinal reflexes in rats by central and peripheral sensory input. J Comp Physiol Psychol 95:548-555.

Steinmetz JE, Lupica CR, Secard CM, Patterson MM (1982) Effects of manipulating stimulation intensity and duration on fixation of a peripherally-induced spinal reflex alteration in rats. Physiol Behav 29:1039-1044.

Steinmetz JE, Beggs AL, Molea D, Patterson MM (1985) Long-term retention of a peripherally induced flexor reflex alteration in rats. Brain Res 327:312-315.
Tai Q, Palazzolo K, Mautes A, Nacimiento W, Kuhtz-Buschbeck JP, Nacimiento AC, Goshgarian HG (1997) Ultrastructural characteristics of glutamatergic and GABAergic terminals in cat lamina IX before and after spinal cord injury. J Spinal Cord Med 3:311-318.

Tillakaratne NJK, Mouria M, Ziv NB, Roy RR, Edgerton VR, Tobin AJ (2000) Increased expression of glutamate decarboxylase (GAD67) in feline lumbar spinal cord after complete thoracic spinal cord transection. J Neurosci Res 59:219-230.

Vanderhorst VG, Holstege G (1997) Organization of lumbosacral motoneuronal cell groups innervating hindlimb, pelvic floor, and axial muscles in the cat. J Comp Neurol 382:46-76.

Wuenschell CW, Fisher RS, Kaufman DL, Tobin AJ (1986) In situ hybridization to localize mRNA encoding the neurotransmitter synthetic enzyme glutamate decarboxylase in mouse cerebellum. Proc Nat Acad Sci USA 83:6193-6197. 